\title{
Trade-offs in means tested pension design ${ }^{\text {is }}$
}

\author{
Chung Tran ${ }^{\mathrm{a}, 1}$, Alan Woodland ${ }^{\mathrm{b}, *}$ \\ a Research School of Economics, The Australian National University, ACT 0200, Australia \\ ${ }^{\mathrm{b}}$ School of Economics and ARC Centre of Excellence in Population Ageing Research (CEPAR), The University of New South Wales, Sydney, \\ NSW 2052, Australia
}

\section{A R T I C L E I N F O}

\section{Article history:}

Received 17 June 2014

Accepted 8 July 2014

Available online 29 July 2014

\section{JEL classification:}

D9

E2

E6

H3

H5

J1

Keywords:

Means-tested pension

Social security

Optimal policy

Overlapping generations

Dynamic general equilibrium

\begin{abstract}
A B S T R A C T
The means-testing of age pension programs allows governments to control the receipt of pension benefits (extensive margin) and the benefit level (intensive margin). We investigate how the presence of the extensive margin influences the trade-off between protecting the poorer elderly and the economic costs of distorting incentives to work and save of young individuals. The means-test effect via the extensive margin improves the insurance aspect but introduces opposing impacts on incentives that potentially have ambiguous welfare outcomes. We characterize combinations of the maximum pension benefit and taper rate that balance the negative incentive effects and positive insurance effects.
\end{abstract}

(c) 2014 Elsevier B.V. All rights reserved.

\section{Introduction}

There is a variety of pension systems across developed countries. Countries such as France, Germany and the U.S.A. have pay-as-you-go (PAYG) pension systems in which coverage is practically universal, and the benefit level is mainly determined by individual contributions over working ages and implicitly means-tested by some redistributive factors. ${ }^{2}$ On other hand, countries such as Australia and the United Kingdom have pension benefit levels that are explicitly means tested and less dependent on individual contributions. The Australian pension system, in particular, has the following distinct features: (i) the pension benefits are dependent on economic status (assets and income); (ii) coverage of the pension system is not universal in that only a fraction of the retiree population, i.e., the poorer elderly, receives pension benefits; (iii) the pension

\footnotetext{
We appreciate comments from seminar participants at the Australian National University, the University of Melbourne, Monash University, Deakin University, and the participants of the Computing in Economics and Finance Conference and Workshop on Macroeconomic Dynamics. This research was supported by the Australian Research Council and the National Health and Medical Research Council.

* Corresponding author. Tel.: +61 293859707.

E-mail addresses: chung.tran@anu.edu.au (C. Tran), a.woodland@unsw.edu.au (A. Woodland).

${ }^{1}$ Tel.: +61 61255638

${ }^{2}$ See Gruber and Wise (1999) for an overview of PAYG pension systems in advanced countries.
} 
benefits are independent of individuals' contribution history; and (iv) the tax financing instrument is not restricted to payroll tax revenue collected from the current working population.

Inclusion of means testing in pension programs allows governments to better direct benefits to those most in need and to control funding costs by providing flexibility to control the condition for receiving benefits (extensive margin) and the benefit level (intensive margin). The basic problem of designing a means-tested pension system is to set the conditions for receiving benefits and the level of benefits in the way that efficiently trades off the desirability of protecting low income elderly (insurance) against the economic cost of distorting effects on labor supply and savings (incentive). In this paper, we study how the design of means testing instruments affects individuals' inter-temporal allocation and utility. Our ultimate goal is to determine how the inclusion of means testing of pension benefits influences trade-offs between insurance and incentive effects and the conditions under which means tested pension systems lead to favorable welfare outcomes.

To that end, we first investigate the effects through intensive and extensive margins of means tested pensions within the framework of a two period, partial equilibrium model based on Varian (1980). In our simple model, means testing of pensions involves the specification of the maximum pension benefit and the taper rate at which benefits are withdrawn for each unit of extra income beyond an income threshold. These policy parameters determine whether an individual receives benefits or not, depending on both the withdrawal or taper rate and the overall magnitude of the benefit. First, we find that the presence of an extensive margin introduces two opposing effects on savings incentives. On one hand, the extensive margin tends to encourage agents to save more to prepare themselves for the possibility that they are not eligible for pensions; on other hand, it tends to induce agents to reduce saving to increase their chances of receiving a pension in retirement. Interestingly, the direction of the extensive margin effect depends on the strength of the intensive margin effect. If the intensive margin effect is relatively less generous, the extensive margin has a positive effect; otherwise, it has a negative effect. The final effect on individuals's savings incentives depends on how these interactions combine. Moreover, we find that limiting benefits towards relatively poorer retirees strengthens the redistributive function of a pension system, with emphasis more on intra-generational redistribution, while keeping the distortionary effects of tax financing relatively small. This subsequently improves risk-sharing across households and generations.

The final judgment regarding the value of a means tested pension program should be based on the welfare effects embodying the trade-off between welfare gains from strengthening the positive insurance effects and welfare losses due to the negative incentive effects. Means testing adds new dimensions to this trade-off between the insurance and incentive effects, but the final welfare outcome depends upon how these new aspects interact with other features of the overall social insurance system and upon the nature of the economy. More specifically, the final welfare effects are influenced by dynamic interactions between these two margins and fundamentals, including preferences, endowments, market structures and institutional features.

Accordingly, in the second part of the paper we focus on exploring quantitative aspects of these trade-offs in a more realistic framework, taking these fundamental factors into account. We follow the tradition of the dynamic general equilibrium literature on social security and formulate an incomplete market, overlapping generations economy with heterogeneous households, a perfect competitive representative firm and a government with a full commitment technology (e.g., Imrohoroglu et al., 1995). In addition, we allow for endogenous retirement and also incorporate the main features of Australia's means tested age pension system. Our benchmark model can match key patterns of life-cycle behavior of Australians as well as essential features of the Australian macroeconomy. We next conduct policy experiments to quantify the effects of the means-tested pension. Our quantitative results are summarized as follows.

In our first experiment, conditioning on the existence of a pension system, we compare steady state results when varying taper rates for the income means test. We find that the presence of taper rates redistributes pension benefits towards relatively poor retirees, which improves allocation of risk across households and generations. On other hand, it results in two opposing effects on individuals' savings and work incentives over their life cycle: one that induces young individuals to work more hours and to save for their retirement, one that induces middle and old-aged individuals to withdraw from the labor force. Overall, we find there is a positive taper rate that balances the negative incentive effects and positive insurance effects, and results in welfare gains.

Next, we compare steady state results of an economy featuring a means tested pension with an economy without a pension. The results reveal that a non-PAYG pension program with means testing instruments results in lower welfare outcomes than having no pension. This implies that means tested pension systems are not socially desirable in our dynamic, general equilibrium model economy, since the adverse effects on incentives dominate the positive social insurance effects of pensions even when they are means tested. Consequently, when the pension program is completely removed, efficiency gains from increases in savings and labor supply result in higher consumption and welfare. This finding is similar to that obtained in the PAYG social security literature.

Finally, we compare steady state results when varying the generosity of the maximum pension and taper rates for the income means test. Interestingly, the introduction of means testing results in non-linear welfare effects of changes in the generosity of the pension system and taper rates. That is, when the maximum pension benefits are relatively small, the introduction of income tests (raising taper rates) always leads to a welfare gain as the positive welfare effects from strengthening risk-sharing and mitigating self-insurance disincentives are always dominant. However, once the pension benefits become more generous, the negative incentive effects become more pronounced as taper rates are increased. The underlying economic mechanism behind this outcome is that the economic distortions of taper rates as implicit taxes on life-cycle savings and labor supply are more severe when pensions are more generous. Conditioning on the level of maximum pension benefits, we find that there is an optimal taper rate that balances these two forces. 
Related literature. The idea of using means tests to limit pension benefits towards old and poor agents is suggested by Friedman and Cohen (1972). However, this conclusion is not generally true, as argued in Feldstein (1987). Feldstein uses a framework with heterogenous preferences (myopes and cyclers) and a very simple means tested pension program. In this setting, the means-tested pension systems works as a device correcting distortions in preferences (short-sighted) on individuals' inter-temporal allocation and utility. By contrast, we conduct our analysis in a moral hazard model of Varian (1980) and in a general equilibrium life cycle model with elastic labor supply as in Imrohoroglu et al. (1995); and we also consider a more complex and realistic means testing rule. We find that a means-tested pension system may not be superior to a universal pension system, which is similar to the finding in Feldstein (1987). We also characterize the conditions under which means testing might lead to a favorable welfare outcome compared to a universal pension system. Indeed, our work extends the analysis in Feldstein (1987) and highlights that the key mechanism in Feldstein (1987) is still applicable in a more general framework.

Recent studies quantifying the effects of means tested pensions on savings, labor supply and welfare in a life cycle framework emphasize the effects of taper rates working through the intensive margin, i.e., imposing an implicit tax. Sefton et al. (2008) use a multi-period overlapping generations model calibrated to the U.K. They find that tightening the taper rate for the income test encourages poor individuals to save more and to delay retirement, while generating opposite effects on the savings and retirement decisions of the rich. Sefton and van de Ven (2009) find that means tested pensions are socially preferred to a universal pension in the U.K. as they deliver better welfare outcomes. Kumru and Piggott (2009) also find a welfare gain from introducing means tests in the U.K. social security system. Maattanen and Poutvaara (2007) find negative welfare effects when introducing labor earnings tests to the PAYG social security system in the U.S.A. Kudrna and Woodland (2011) analyze the general equilibrium effects of changing taper rates of the Australian pension system in a deterministic overlapping generations model. It is noteworthy that these papers abstract from an important channel of effects via the extensive margin. In contrast, our research extends these papers by highlighting the importance of the extensive margin effects. We show that the interactions between taper rates and the maximum pension benefit via the extensive margin results in opposing effects on individuals' incentives. Subsequently, the welfare effects of changes in taper rates vary significantly over the levels of maximum pension benefits.

Our study is also related to the large literature that undertakes dynamic, general equilibrium analyses of PAYG social security systems (e.g., see Auerbach and Kotlikoff, 1987; Hubbard and Judd, 1987; Imrohoroglu et al., 1995; Conesa and Krueger, 1999; Krueger and Kubler, 2006; Fuster et al., 2007). This literature focuses on the U.S. social security system in which the coverage is universal, and it therefore excludes the effects coming from the extensive margin. Our study is complementary to that literature as we examine a pension system in which the extensive and intensive margins are both relevant. We demonstrate that these two margins matter for welfare outcomes.

Our paper is also linked to the literature on social insurance with means testing, which has focused mainly on disability insurance. Diamond and Mirrlees (1978) and Diamond and Mirrlees (1986) conclude that optimal benefits are structured so that the healthy are indifferent as to whether to mimic the disabled or continue working. In a more recent work on optimal disability insurance, Golosov and Tsyvinski (2006) argue that disability insurance benefits should be asset-tested to prevent individuals from claiming benefits when, optimally, they should not. Our paper follows a similar approach, but focuses on a pension program.

The paper is structured as follows. In Section 2 we present a simple model to highlight the role played by the intensive and extensive margins. In Section 3 we set up a dynamic, general equilibrium model. Section 4 describes details of our calibration of the model to the Australian economy, while Section 5 contains the discussion of a range of policy experiments and results. We present conclusions in Section 6. The Appendix provides mathematical details for the theoretical model and solution algorithm for the dynamic general equilibrium model.

\section{A simple model economy}

In this section, we specify a theoretical model and use it to highlight how the inclusion of means testing into the age pension benefit formula influences individuals' incentives to save over the life cycle. This simple model, based on Varian (1980), captures essential aspects of the problem that motivates a society's desire for social insurance and provides a convenient framework in which to explain that there are two margins of interest when means-tested benefits are introduced. In doing so, we are able to emphasize the essential role played by means testing on the intensive and extensive margins related to pension receipts by the elderly. ${ }^{3}$

\subsection{Environment}

We consider a simple partial equilibrium economy comprised of agents living for two periods with endowment incomes of $w_{1}$ and $w_{2}$ in period 1 and 2, respectively. At the beginning of period 1 an agent receives income $w_{1}$ and makes a decision on consumption and saving to maximize expected utility, taking the income distribution $f\left(w_{2}\right)$ in period 2 and the

\footnotetext{
${ }^{3}$ In this section, we abstract from the labor/leisure decision to keep the model sufficiently simple to highlight the channels by which the design of a means-test pension distorts the savings decision. The labor/leisure choice could readily be included, but at the cost of simplicity.
} 
government pension policy as given. The individual agent's optimization problem is

$$
\max _{c_{1}, c_{2}, s}\left\{u\left(c_{1}\right)+p \operatorname{Eu}\left(c_{2}\right): c_{1}+s=w_{1}-g\left(\tau, w_{1}\right) \quad \text { and } \quad c_{2}=w_{2}+(1+r) s+P\right\},
$$

where $p$ is survival probability, $c_{1}$ is consumption when young, $s$ is saving, $c_{2}$ is consumption when old, $r$ is the market rate of return on savings, $g\left(\tau, w_{1}\right)$ is the tax function with tax rate $\tau$ and $P$ is an individual specific pension benefit. We consider a general function for the means-tested pension payment

$$
P= \begin{cases}P^{\max }-\omega\left(w_{2}+\xi r s\right) & \text { if } w_{2}+\xi r s<\bar{y}_{2}, \\ 0 & \text { if } w_{2}+\xi r s \geq \bar{y}_{2},\end{cases}
$$

where $\left(w_{2}+\xi r s\right)$ is the testable income, which includes two components: labor endowment income in period 2 and interest from saving in period $1 . \xi$ is an indicator: $\xi=0$ if saving is excluded; otherwise, $\xi=1$.

To aid the exposition, we assume that individuals have quadratic preferences given by $u(c)=-c^{2} / 2+\chi c$, where $\chi>0$, and that wage income in period 2 follows a uniform distribution $f\left(w_{2}\right)=1 / w_{2}^{\max }$. Thus, the expected wage income when old is $E\left(w_{2}\right)=w_{2}^{\max } / 2 \equiv \bar{w}_{2}$. For ease of exposition, we also assume (except in one case further below) that rate of return on investment is $r=0$ and that the survival probability is $p=1$, guaranteeing that the economy is dynamically efficient so that the pension system fails to yields a higher rate of return. Optimal saving is now implicitly given by

$$
s=\frac{[1+(1-\xi \omega) r][\overbrace{\left[\frac{\widehat{w}_{2}}{2}+P^{\text {max }}-\omega \frac{\widehat{w}_{2}}{2}\right]}^{\text {Average income }} \overbrace{\pi^{p}}^{\text {Pensioner }}-(1+r) \overbrace{(w_{2}^{\text {max }}+\frac{\left.\widehat{w}_{2}\right)}{2} \overbrace{\left(1-\pi^{p}\right)}^{\text {Probability }}}^{\text {Pensioner }}}{1+\overbrace{[1+(1-\xi \omega) r]^{2} \pi^{p}}^{\text {Average income }}+\overbrace{(1+r)^{2}\left(1-\pi^{p}\right)}^{\text {Non-Pensioner }}},
$$

where the probability of being a pensioner is $\pi^{p}=\widehat{w}_{2} / w_{2}^{\max }, \widehat{w}_{2}=\bar{y}_{2}-\xi$ rs and the tax function is assumed to be $g\left(w_{1}, \tau\right)=\tau w_{1}$. Note that the probability of being a pensioner, $\pi^{p}=\pi\left(\bar{y}_{2}, s\right)$, is dependent on the individual's saving, since the wage rate that separates pensioners from non-pensioners, $\widehat{w}_{2}$, depends on the level of saving. ${ }^{4}$

\subsection{Extensive margin and savings}

Inclusion of means-testing instruments $\left(P^{\max }, \omega, \bar{y}_{2}\right)$ results in two separate channels of effects: (i) the condition for receiving pension benefits, i.e., the fraction of agents participating in a public pension program (extensive margin); and (ii) the level of pension benefits (intensive margin). The former is governed by income threshold and savings $\pi^{p}=\pi\left(\bar{y}_{2}, s\right)$, while the latter is determined by the maximum pension benefits and taper rate $\left(P^{\max }-\omega \widehat{w}_{2} / 2\right)$. In a context where the government sets $\bar{y}_{2}=w_{2}^{\max }$ or $\bar{y}_{2}=0$, the probability of being a pensioner is 1 , i.e., $\pi^{p}=1$. The extensive margin disappears and the means-tested pension system collapses to a universal PAYG pension. In a context where the government sets $\bar{y}_{2} \in\left(0, w_{2}^{\max }\right)$, the extensive margin does exist.

To identify the channels through which means testing instruments impact upon individuals' saving incentives, we first consider the case where savings is excluded from testable income, i.e., $\pi^{p}=\pi\left(\bar{y}_{2}\right)$. We take the first derivatives of the saving function with respect to the maximum pension benefit, $\partial s^{*} / \partial P^{\max }$, and the income test threshold, $\partial s^{*} / \partial \bar{y}_{2}$. The former reflects the effect from the intensive margin, while the latter captures the effect from the extensive margin (hereafter called the intensive margin and extensive margin effects, respectively). Not surprisingly, we find that the effect through the intensive margin is negative as $\partial s^{*} / \partial P^{\max }<0$. This indicates that a public pension program crowds out private savings via the intensive margin even with means testing. However, the sign of the extensive margin effect is ambiguous, since $\partial s^{*} / \partial \bar{y}_{2}=\frac{1}{2} 1 / w_{2}^{\max }\left(\bar{w}_{2}-\left(P^{\max }-\omega \bar{y}_{2} / 2\right)\right) \lesseqgtr 0$. Indeed, it is dependent on the magnitude of the maximum pension benefit, $P^{\max }$, relative to the average income in period $2, \bar{w}_{2}$. This distance $\left[\bar{w}_{2}-\left(P^{\max }-\omega \bar{y}_{2} / 2\right)\right]$ also measures the generosity of the public pension program, i.e., relative strength of the intensive margin effect. As $P^{\max }$ becomes relatively more generous, the strength of the intensive margin effect becomes relatively larger. For example, when the maximum pension benefit is higher than the average income in period $2, P^{\max }>\bar{w}_{2}+\omega \bar{y}_{2} / 2$, the pension system is very generous. The direction of the extensive margin effect depends on the strength of the intensive margin effect. If the intensive margin effect is relatively less generous $\left(P^{\max }<\bar{w}_{2}+\omega \bar{y}_{2} / 2\right)$ the extensive margin effect is positive; otherwise, it is negative.

We now turn to the case where the probability of being a pensioner is dependent on the individual's interest income, $\pi^{p}=\pi\left(\bar{y}_{2}, s\right)$. Under this new means testing policy, the government can no longer directly control the number of pensioners in the economy, since the testable income used by the government to determine the number of agents eligible for the pension program is now dependent upon both the level of labor income endowment in old age (assumed exogenous) and optimal savings of the agents when young (which is endogenous), i.e., upon $w_{2}+r s$. This creates another channel through which the means test impacts on the saving decision. Higher saving directly reduces the probability of becoming a pensioner (extensive margin) and, if the individual is a pensioner, directly reduces the pension payment (intensive margin). In such an environment, individuals optimize their savings for retirement taking into account the saving effect upon the

${ }^{4}$ See Appendix A.1 for a complete equilibrium solution. 
Table 1

Welfare effects for alternative pension parameters.

\begin{tabular}{llllllll}
\hline Taper Rate & \multicolumn{7}{c}{ Replacement Rate $(\Psi)$} \\
\cline { 2 - 8 }$(\omega)$ & 0 & 0.1 & 0.2 & 0.3 & 0.4 & 0.6 & 0.8 \\
\hline \hline 0.0 & -0.8639 & -0.8639 & -0.8639 & -.8680 & -0.9431 & -1.8092 & -7.0430 \\
0.1 & -0.8639 & -0.8555 & -0.8550 & -0.8554 & -0.9073 & -1.5458 & -3.7981 \\
0.2 & -0.8639 & -0.8515 & -0.8479 & -0.8471 & -0.8791 & -1.3622 & -2.6502 \\
0.3 & -0.8639 & -0.8511 & -0.8435 & -0.8410 & -0.8579 & -1.2288 & -2.0670 \\
0.4 & -0.8639 & $\mathbf{- 0 . 8 5 2 3}$ & -0.8414 & -0.8369 & -0.8429 & -1.1290 & -1.7173 \\
0.5 & -0.8639 & -0.8539 & $\mathbf{- 0 . 8 4 1 0}$ & -0.8345 & -0.8337 & -1.0531 & -1.4868 \\
0.6 & -0.8639 & -0.8556 & -0.8416 & $\mathbf{- 0 . 8 3 3 4}$ & -0.8291 & -0.9950 & -1.3255 \\
0.7 & -0.8639 & -0.8570 & -0.8428 & -0.8334 & -0.8279 & -0.9503 & -1.2082 \\
0.8 & -0.8639 & -0.8582 & -0.8443 & -0.8341 & $-\mathbf{- 0 . 8 2 7 7}$ & -0.9156 & -1.1206 \\
0.9 & -0.8639 & -0.8592 & -0.8459 & -0.8352 & -0.8282 & -0.8888 & -1.0533 \\
1.0 & -0.8639 & -0.8600 & -0.8475 & -0.8366 & -0.8291 & $\mathbf{- 0 . 8 6 8 5}$ & $\mathbf{- 1 . 0 0 0 8}$ \\
\hline
\end{tabular}

expected pension payment through the effect on both the intensive and extensive margins. Yet, individuals can manage their savings decision to increase the probability of being a pensioner by decreasing saving. In that sense, the effect of the means test on savings through the extensive margin tends to be negative. On other hand, decreasing the probability of being a pensioner lowers expected income in period 2, which may encourage individuals to save more.

Hence, we have shown that this aspect of the means test leads to two opposing effects on self-insurance incentives to save. The final effect on savings depends on which effect is dominant and how the intensive margin effect interacts with the extensive margin effect.

\subsection{Welfare implication}

In our simple setting considered here, there is classic trade-off between the risk sharing effects and the savingdisincentive effects that underlies how much social insurance should be provided through a means-tested pension system. In particular, means testing instruments limiting pension benefits to a sub-group of the retired population (extensive margin) and providing progressive pension benefits (intensive margin) strengthen the insurance role, which is welfare improving. On other hand, as discussed above, the introduction of a taper rate distorts allocation of income over the life cycle and this might have negative welfare effects. When welfare gains from risk-sharing outweigh welfare losses resulting from distorted saving, there is a positive overall welfare effect and so there is a demand for means-tested pensions as social insurance.

To better understand welfare outcomes when this mechanism is included, we consider a numerical example. We assume standard CRRA preferences in the form of $u(c)=c^{1-\sigma} /(1-\sigma)$ with $\sigma=2$. Income endowments are homogeneous in period 1 and set at $w_{1}=2.7$, but are heterogeneous in period 2 with $w_{2}$ following a log normal distribution with mean $\mu_{w_{2}}=1$ and standard deviation $\sigma_{w_{2}}=2$. The interest rate is normalized to zero $(r=0)$ for simplicity and individuals are not allowed to borrowed.

We numerically explore how different designs of a means-tested pension program affect social welfare, by choosing different policy parameter values of maximum pension payment $P^{\max }$ and taper rates $\omega$. We index the maximum pension payment, $P^{\max }$, to average income, $\bar{y}$, by specifying $P^{\max }=\Psi \bar{y}$, where $\Psi$ is a replacement rate. We consider a range of replacement rates $\Psi$ between 0 and 0.8 , and a range of taper rates $\omega$ between 0 and 1 . The government uses payroll tax as a financing instrument. Social welfare is measured in terms of the expected utility of a newborn agent. Table 1 presents different policy choices of maximum pension benefits by columns and different policy choices of taper rates by rows.

We start with social welfare in an economy with no pension as in the first cell of row 1 of Table 1 and introduce a universal social security program by raising $P^{\max }$. As seen in row 1 of Table 1 , the introduction of a universal pension program always lead to lower welfare, i.e., social welfare is a decreasing function of maximum pension benefits. The intuition is as follows. In our setting, the universal pension program does not have any distributional effect as agents contribute identical amounts of tax income to the program and receive identical benefits regardless of their income status (i.e., no insurance effect). Consequently, since the universal pension program distorts the savings incentive while providing no risk-sharing mechanism, it results in lower welfare.

Next, we deviate from a universal pension program and allow the government to use income tests to determine social security benefits: individuals with higher incomes receive smaller benefits. This discrimination keeps the extensive margin in play, which in return makes pension schemes progressive and, hence, triggers trade-offs between the insurance effect and the incentive effect. The presence of the extensive margin strengthens the progressiveness of the pension benefits, 
which improves risk-sharing across households and generations. Comparing results for $\omega=0.1,0.2$ and 0.3 in rows $2-5$ (means-tested pension) with those for $\omega=0$ in row 1 (universal pension) in Table 1, we find that a means-tested social security program results in higher social welfare compared to a universal pension. This indicates that means-tested social security programs are strictly preferred to universal pension programs for a wide range of policy parameter values in our model.

The social welfare outcome is determined by the trade-off between insurance and incentive effects working through extensive and intensive margins in our framework. Varying taper rates affects coverage of social insurance programs (extensive margin). To explore the role of extensive margin quantitatively, we first keep maximum pension benefits unchanged and vary taper rates. By examining each column in Table 1 for various maximum pension benefit levels, we find a trade-off between insurance and incentive effects as taper rates increase. When maximum pension payments are small (for example, when $0<\Psi \leq 0.4$ ), increases in the taper rate generate higher welfare initially and then lower welfare for higher taper rates. This implies that there is an optimal taper rate that yields highest social welfare, taking the maximum pension as given. However, this result is not true when the maximum benefit payment is sufficiently large $(\Psi>0.4)$, in which case increases in the taper rate always results in higher welfare. This means that when the incentive effect is already dominant, the government could increase taper rates to neutralize some of these distortions.

Fourth, we examine the effects of increasing maximum pension benefits while keeping the taper rate unchanged. The welfare effects are indicated by examining each row of Table 1 for various taper rates. As previously noted, social welfare declines as $P^{\max }$ increases for the case when $\omega=0$ (row 1 ). However, when $\omega>0$ we see hump-shaped patterns of the social welfare function, initially rising as a function of the maximum pension benefit and then declining. This illustrates numerically the interplay of the insurance and incentive effects upon social welfare. When the insurance effect is dominant, increasing the maximum pension raises social welfare; when the incentive effect is dominant, higher maximum pension benefits result in lower welfare. More specifically, when the maximum pension is relatively small the insurance effects are still dominant and therefore increases in maximum pension still lead to higher welfare. On other hand, when the maximum pension is relatively large, the disincentive effects are a dominating force and therefore further increases in the maximum pension benefit decrease welfare.

Overall, we find in our numerical example that a means tested pension system results in a superior social welfare outcome, compared to either no pension or a universal pension system. It is always the case that means testing (at any taper rate) is better than a universal pension (each row element is larger than the first row in every column). For all maximum pension benefits with a replacement rate less than $\Psi \leq 0.5$ there are taper rates that yield better welfare outcomes than obtained with no pension. However, we also find cases, when maximum pension benefit is very generous, in which social welfare is lower than obtained with no pension or with a universal pension. Thus, an optimal design of a means tested pension program is obtained when the system efficiently trades off between insurance and incentive effects.

To make a judgment on the effects of a means tested pension program, one should seriously account for fundamentals of the economy, such as preferences, endowments, market structure and institutional settings. In the next section, we develop a dynamic, general equilibrium model of an economy in which we take into account these factors.

\section{A dynamic general equilibrium model}

We formulate a small open economy overlapping generations dynamic general equilibrium model, which consists of heterogeneous households, a perfect competitive representative firm, and a government with full commitment technology.

\subsection{Demographics}

The economy is populated by agents (households) whose ages are denoted by $j \in[1, \ldots, J]$. Each period a continuum of agents of age 1 are born. The population grows at an exogenous annual rate, $n$. All agents face an age-dependent survival probability, $s p_{j}$, and live at most $J$ periods. When the demographic pattern is stationary, as assumed here, the population share of the cohort age $j$ is constant at any point in time and can be recursively defined as $\mu_{j}=\mu_{j-1} s p_{j} /(1+n)$. The share of agents who do not survive to age $j$ is $\tilde{\mu}_{j}=\mu_{j-1}\left(1-s p_{j}\right) /(1+n)$.

\subsection{Preferences}

All agents have identical lifetime preferences over consumption $c_{j} \geq 0$ and leisure $l_{j}$, where household leisure time per period for household $j$ is constrained by $0<l_{j} \leq 1$. Preferences are time-separable with a constant subjective discount factor $\beta$ and are given by the expected utility function

$$
E\left[\sum_{j=1}^{J} \beta^{j} s p_{j} u\left(c_{j}, l_{j}\right)\right] .
$$




\subsection{Endowments}

Agents are born with a specific skill type that determines their labor productivity over the life cycle. This skill type is predetermined and unchanged over the life span. We let $\varrho$ denote an individual's skill type, and consider three types: low, medium and high skills, i.e., $Q \in\{$ Low, Medium, High $\}$.

In each period of life agents are endowed with 1 unit of labor time that has labor efficiency (or working ability or labor productivity) denoted by $e_{j}$. The efficiency unit $e_{j}=e(\varrho, j)$ is skill and age dependent and follows a Markov switching process with $\pi_{j}\left(e_{j+1 \mid} e_{j}\right)$ denoting the conditional probability that a person of working ability $e_{j}$ at age $j$ will have working ability $e_{j+1}$ when at age $j+1$. According to this specification, agents have working abilities that vary by age and change stochastically over the life cycle; they therefore face idiosyncratic earnings risk, which is assumed to be non-insurable. The quantity of an agent's period effective labor services is $h_{j}=\left(1-l_{j}\right) e_{j}$.

\subsection{Technology}

The production sector consists of a large number of perfectly competitive firms, which is formally equivalent to one aggregate representative firm that maximizes profits. The production technology of this firm is given by a constant returns to scale production function $Y=A F(K, L)$, where $K$ is the input of capital, $L$ is the input of effective labor services (human capital) and $A$ is the total factor productivity, assumed to be growing at a constant rate, $g$. Capital depreciates at rate $\delta$. The firm chooses capital and labor inputs to maximize its profit according to $\max _{K, L}\{A F(K, L)-q K-w L\}$, given rental rate, $q$, and market wage rate, $w$.

\subsection{Fiscal policy}

In the benchmark economy, the government operates a means tested pension system and a tax system similar to the current Australian system.

Means-tested pension. The old-age pension (social insurance) system is not universal but targets households who have low private retirement incomes through the use of income and assets means tests. The amount of pension benefit $\mathcal{P}\left(a_{j}, y_{j}\right)$ received at age $j$ varies across individuals and depends on the asset and income tests as

$$
\mathcal{P}\left(a_{j}, y_{j}\right)=\min \left\{\mathcal{P}^{a}\left(a_{j}\right), \mathcal{P}^{y}\left(y_{j}\right)\right\},
$$

where $\mathcal{P}^{a}\left(a_{j}\right)$ is the asset test pension and $\mathcal{P}^{y}\left(y_{j}\right)$ is the income test pension. Accordingly, the pension benefit is the smaller of the two pension rates; the strictest test binds. The pension benefit arising from the asset test is given by

$$
\mathcal{P}^{a}\left(a_{j}\right)= \begin{cases}P^{\max } & \text { if } a_{j} \leq \bar{a}_{1}, \\ P^{\max }-\omega_{a}\left(a_{j}-\bar{a}_{1}\right) & \text { if } \bar{a}_{1}<a_{j}<\bar{a}_{2}, \\ 0 & \text { if } a_{j} \geq \bar{a}_{2},\end{cases}
$$

where $\bar{a}_{1}$ and $\bar{a}_{2}=\bar{a}_{1}+P^{\max } / \omega_{a}$ are the asset thresholds and $\omega_{a}$ is the asset taper rate indicating the amount by which the pension is decreased for each additional unit of asset above the low asset threshold. Similarly, the pension benefit based on the income test is given by

$$
\mathcal{P}^{y}\left(y_{j}\right)= \begin{cases}P^{\max } & \text { if } y_{j} \leq \bar{y}_{1}, \\ P^{\max }-\omega_{y}\left(y_{j}-\bar{y}_{1}\right) & \text { if } \bar{y}_{1}<y_{j}<\bar{y}_{2}, \\ 0 & \text { if } y_{j} \geq \bar{y}_{2},\end{cases}
$$

where $\bar{y}_{1}$ and $\bar{y}_{2}=\bar{y}_{1}+P^{\max } / \omega_{y}$ are the income thresholds, $\omega_{y}$ is the income taper rate indicating the amount by which the pension is reduced for each additional unit of income above the low income threshold, $\bar{y}_{1}$.

Taxation. The government levies taxes on consumption and income to finance general government consumption and the old-age pension program. The consumption tax rate is set at $\tau^{c}$. The income tax schedule is progressive and compactly written as

$$
T\left(y_{j}\right)=T_{k}+\tau_{k}\left(y_{j}-\bar{y}_{k}\right), \quad y_{j} \in\left[\bar{y}_{k}, \bar{y}_{k+1}\right],
$$

where the parameters of this tax function are the marginal tax rates, $\tau_{\mathrm{k}}$, the tax payment thresholds, $T_{k}$, and the tax bracket income thresholds, $\bar{y}_{k}$. It is assumed that $\tau_{1}=0, T_{1}=T_{2}=0$ and $T_{k}=T_{k-1}+\tau_{k}\left(\bar{y}_{k}-\bar{y}_{k-1}\right)$. This specification corresponds to a standard segmented-linear income tax schedule with an initial tax free threshold and marginal tax rates that rise with taxable incomes. The income tax is set so that the consolidated government budget constraint is satisfied every period, whence

$$
\overbrace{\sum_{j} T\left(y_{j}\right) \mu\left(x_{j}\right)}^{\text {Income tax revenue }}+\overbrace{\sum_{j} c_{j}\left(x_{j}\right) \mu\left(x_{j}\right)}^{\text {Consumption tax revenue }}=\overbrace{\sum_{j} \mathcal{P}\left(x_{j}\right) \mu\left(x_{j}\right)}^{\text {Pension payment }}+\overbrace{G}^{\text {General government expenditures }},
$$

where, $\mu\left(x_{j}\right)$ is the measure of agents in state $x_{j}$. 


\subsection{Market structure}

Markets are incomplete and households cannot insure against the idiosyncratic labor income and mortality risks by trading state contingent assets. They can, however, hold one-period riskless assets to imperfectly self-insure against idiosyncratic risks. We assume that agents are not allowed to borrow against future income, implying asset holdings are non-negative, i.e., $a_{j} \geq 0$ for all $j$.

The economy is assumed to be a small open economy in the sense that all agents in the economy take the world prices for internationally traded goods and the world interest rate on bonds, $r$, as given and independent of the amount of trade in these goods and bonds. The free flow of financial capital ensures that the domestic interest rate is equal to the world interest rate, which is assumed to be constant. An implication is that the rental price of capital is then given by $q=r+\delta$.

\subsection{Household problem}

Households are heterogeneous with respect to their state variables including skill, age, working ability and asset holdings. Let $x_{j}=\left(e_{j}, a_{j}\right)$ denote the household's state variables at age $j$. At the beginning of age $j$ the household realizes its individual state $x_{j}=\left(e_{j}, a_{j}\right)$ and chooses its optimal consumption, $c_{j}$, leisure time, $l_{j}$, or working hours, $\left(1-l_{j}\right)$, and the end-ofperiod asset holdings, $a_{j+1}$, taking the transition law for working ability, $\pi_{j}\left(e_{j+1 \mid} e_{j}\right)$, conditional survival probabilities, $s p_{j}$, the wage and interest rates, and government tax and pension policies as given. Notice that we consider both margins of labor supply. When the agent chooses to allocate all time to leisure $\left(l_{j}=1\right)$, the agent exits the labor market and has retired. There is no mandatory retirement age so agents may stay in the labor force as long as they choose. The retirement age is endogenously determined, e.g., extensive margin. However, retirement is not required to be irreversible since households may re-enter the labor market.

Households have three sources of income: labor earnings, savings and transfers. First, if households decide to work they supply $\left(1-l_{j}\right) e_{j}$ units of effective labor service to the labor market, attract a wage rate $w_{t}$ and so earn a gross wage income or labor earnings of $\left(1-l_{j}\right) e_{j} w_{t}$. Second, households have the cash balance from savings income available to spend in the amount $(1+r) a_{j}$. Third, eligible households may receive old-age pension transfers from the government in amount $P_{j}$. Specifically, agents who are $J_{1}=65$ years of age or older are entitled to receive the old-age pension. There is a maximum amount of pension income, $P^{\max }$, but the actual amount of pension benefit varies across individuals and depends on the asset and income tests as $P_{j}=\mathcal{P}\left(a_{j}, y_{j}\right)$, where assessable income for the pension income test is simply labor and interest earnings, $y_{j}=e_{j}\left(1-l_{j}\right) w+r a_{j}$. Finally, households receive accidental bequests, $b_{j}$, as a lump-sum transfer from the government.

Formally, the life-cycle expected utility maximization problem of agent $i$ can be expressed recursively as

$$
V^{j}\left(x_{j}\right)=\max _{c_{j}, l_{j}, a_{j+1}}\left\{u\left(c_{j}, l_{j}\right)+\beta s p_{j} E\left[V^{j+1}\left(x_{j+1}\right) \mid e_{j}\right]\right\}
$$

subject to the following constraints for every $j \in J$

$$
\begin{aligned}
& a_{j+1}=\frac{1}{(1+g)}\left[a_{j}+e_{j}\left(1-l_{j}\right) w+r a_{j}+b_{j}+\mathcal{P}\left(a_{j}, y_{j}\right)-T\left(y_{j}\right)-\left(1+\tau^{c}\right) c_{j}\right], \\
& a_{1}=0, \quad a_{J}=0, \quad a_{j} \geq 0, \\
& 0<l_{j} \leq 1,
\end{aligned}
$$

where $E\left[V^{j+1}\left(x_{j+1}\right) \mid e_{j}\right]$ is the expected value function, $T\left(y_{j}\right)$ is income tax payment and $\tau^{c}$ is the consumption tax rate. Note that individual quantity variables, except for working hours, are normalized by the steady state per capita growth rate, $g$.

\subsection{Equilibrium}

Given government policy settings for tax rates and the old-age pension system, the population growth rate, world interest rate, a steady state competitive equilibrium is such that

(a) a collection of individual household decisions $\left\{c_{j}\left(x_{j}\right), l_{j}\left(x_{j}\right), a_{j+1}\left(x_{j}\right)\right\}_{j=1}^{J}$ solve the household problem (10); ${ }^{5}$

(b) the firm chooses labor and capital inputs to solve the profit maximization problem;

(c) the total lump-sum bequest transfer is equal to the total amount of assets left by all the deceased agents, $B=\sum_{j \in J} \tilde{\mu}_{j} \int_{\Phi} a_{j}\left(x_{j}\right) d \Lambda_{j}\left(x_{j}\right)$

(d) the current account is balanced and foreign assets, $F A$, freely adjust so that $r=r^{w}$, where $r^{w}$ is the world interest rate;

(e) the domestic markets for capital and labor clear

$$
K=\sum_{j \in J} \mu_{j} \int_{\Phi} a_{j}\left(x_{j}\right) d \Lambda_{j}\left(x_{j}\right)+B+F A,
$$

\footnotetext{
${ }^{5}$ In the following, endogenous variables for the household of age $j$ are shown with dependence on the vector of state variables, $x_{j}=\left(e_{j}, a_{j}\right)$, at that age.
} 
Table 2

Preference, technology, demography and policy parameters.

\begin{tabular}{|c|c|c|}
\hline Parameters & Model & Observation/Comment/Source \\
\hline \multicolumn{3}{|l|}{ Preferences } \\
\hline Annual discount factor & $\beta=0.98$ & To match $I / Y$ \\
\hline Inverse of inter-temporal elasticity of substitution & $\sigma=4$ & \\
\hline Share parameter for leisure & $\gamma=0.18$ & To match labor supply profile \\
\hline \multicolumn{3}{|l|}{ Technology } \\
\hline Annual growth rate & $g=0.033$ & $3.3 \%$ \\
\hline Total factor productivity & $A=1$ & \\
\hline Share parameter of capital & $\alpha=0.4$ & \\
\hline Annual depreciation rate & $\delta=0.055$ & $5.5 \%$ \\
\hline \multicolumn{3}{|l|}{ Demography } \\
\hline Maximum lifetime & $J=14$ & Equivalent to 70 years \\
\hline Maximum working period & $J_{w}=9$ & Equivalent to 45 years \\
\hline Annual population growth & $n=0.012$ & $1.2 \%$ \\
\hline \multicolumn{3}{|l|}{ Government } \\
\hline Income taxes & $\tau_{j}, T_{j}, \bar{y}_{j}$ & Tax schedules in 2007 \\
\hline Medicare levy & $\tau^{\mathrm{Med}}=0.015$ & $1.5 \%$ \\
\hline Consumption tax & $\tau^{c}$ & Endogenous \\
\hline Pensions & $P^{\max }, \omega_{y}=0.4$ & Pension rules in 2007 \\
\hline Government consumption & $\Delta_{G}=0.14$ & To match government size \\
\hline
\end{tabular}

$$
H=\sum_{j \in J} \mu_{j} \int_{\Phi}\left(1-l_{j}\right) e_{j}\left(x_{j}\right) d \Lambda_{j}\left(x_{j}\right),
$$

and factor prices are determined competitively, i.e., $w=F_{L}(K, L), q=F_{K}(K, L)$ and $r=q-\delta$; and

(f) the government budget constraint defined in Eq. (9) is satisfied.

\section{Calibration}

This section describes the calibration and parameterization of the model. We calibrate our benchmark model to match the Australian economy and report the values of key parameters of the benchmark model in Table 2.

\subsection{Demographics}

One model period corresponds to 5 years. Households become economically active at age $20(j=1)$ and live up to the maximum age of 90 years (equal to the maximum model period $J=14$ ). The survival probabilities are calculated from life tables for Australia. The annual growth rate of the new born agents (households) is assumed to be $1.2 \%$, which is the longrun average population growth in Australia.

\subsection{Preferences}

Instantaneous utility obtained from consumption and leisure is defined as

$$
u\left(c_{j}, l_{j}\right)=\frac{\left[\left(\left(1+d p_{j}\right)^{\eta} c_{j}\right)^{\gamma}\left(l_{j}\right)^{1-\gamma}\right]^{1-\sigma}}{1-\sigma},
$$

where $\gamma$ is the weight on utility from consumption relative to that from leisure, $\sigma$ is the coefficient of relative risk aversion, $d p_{j}$ is the number of dependent children at age $j$ and $\eta$ is the demographic adjustment parameter for consumption. The utility function has the constant relative risk aversion (CRRA) form. We follow previous studies (e.g., Auerbach and Kotlikoff, 1987) and set the relative risk aversion coefficient to $\sigma=4$, which implies an inter-temporal elasticity of substitution of 0.25 . We follow Nishiyama and Smetters (2007) and set $\eta=0.6$. We calibrate $\gamma$ to match average work hours. The subjective discount factor $\beta$ is calibrated to match Australia's net investment to GDP ratio, which has averaged around 0.27 since 1990 according to Australian Bureau of Statistics (ABS) data. The number dependent children $d p_{j}$ is calculated from data in the Household, Income and Labour Dynamics in Australia (HILDA), using the average numbers of children of ages 0-19 in each age group, $j .^{6}$

\footnotetext{
${ }^{6}$ See Wooden et al. (2002) for a more detailed description of the Household, Income and Labour Dynamics in Australia (HILDA).
} 


\subsection{Endowments}

We use estimates of working abilities (i.e., labor productivities) using data drawn from HILDA data for our model calibration. HILDA is a broad social and economics longitudinal survey, with particular attention paid to family and household formation, income and work. We use data from the first 7 waves of HILDA surveys in this paper.

We distinguish 3 skill groups of workers according to their educational levels, so that $Q=\{$ Low, Medium, High $\}$. Low stands for no education, primary education and some secondary education, Medium stands for complete secondary education and High stands for tertiary education. The fractions of Low, Medium, and High skill workers are 23.2, 50.4 and 26.4 percent, respectively.

Work abilities of three permanent skill types evolve over age. Conditioning on skill type, we estimate age-dependent work abilities using average hourly wage estimates per permanent skill group $\varrho$ and age $j$ from HILDA data. For each skill type, we discretize the labor productivity shocks into three states. The Markov transition matrix, $\pi_{j}\left(e_{j+1 \mid} e_{j}\right)$, that characterizes the dynamics of working abilities over life cycle is estimated by a counting method. To make the transition matrix more persistent we use the average of these estimates. We also make an assumption that labor productivities from 65 decline at a constant rate, reaching zero at age 80 years. $^{7}$

\subsection{Technology}

We assume the production functions has a form of $Y=A K^{\alpha} L^{1-\alpha}$, where $K$ is the input of capital, $L$ is the input of effective labor services (human capital) and $A$ is the total factor productivity. We set the capital share of output $\alpha=0.4$. The depreciation rate for capital is determined by the steady state condition and is $\delta=0.055$. The average annual GDP per capita growth rate in Australian is 3.3 percent so we set $g=0.033$. The total factor productivity $A$ is a scaling parameter.

\subsection{Fiscal policy}

We use the Australian tax and pension policy parameter values in 2007 to calibrate fiscal policy in the model.

Means-tested pension. In Australia, the maximum pension is calculated by the formula $P^{\max }=0.25 \times M T A W E$, where MTAWE is Male Total Average Weekly Earnings. We assume that MTAWE is the average labor income $\bar{y}$ and the replacement rate is $\Psi=0.25$. In our benchmark model, the maximum pension is defined by $P^{\max }=0.25 \bar{y}$. The maximum pension is set at $P^{\max }=\$ 13,314.6$. In 2007-2008 the income test threshold is set at $\$ 3328$ and incomes over these amounts reduce the age pension by $\$ 0.4$ for every $\$ 1$. Thus, the income test threshold income is set at $\bar{y}_{1}^{p}=\$ 3328$ and the income taper rate is $\omega_{y}=0.4$. For the asset test, the design is relatively more complicated. There are separate asset tests for renters and homeowners in Australia. In our model, there is no difference between residential and non-residential assets so we are not able to directly use the statutory asset test thresholds. Instead, we choose the threshold $\bar{a}_{1}$ to match the fraction of pensioners at age 65 years. Assets over this threshold reduces pension by $\$ 1.50$ per fortnight for every $\$ 1000$ above the limit, implying a taper rate for asset tests of $\omega_{a}=0.0015$.

Taxation. The government collects tax from consumption and income to cover spending on pension and other government spending programs. The consumption tax rate is set at 10 percent, which is the statutory goods and services (GST) rate in Australia. The Australian income tax schedule is progressive. We use the tax schedules for 2007-2008 in the benchmark model so that the tax function is given by

$$
T(y)= \begin{cases}0 & \text { if } y<\$ 6000 \\ 0.15(y-\$ 6000) & \text { if } \$ 6000<y \leq \$ 25,000 \\ \$ 3600+0.3(y-\$ 30,000) & \text { if } \$ 25,000<y \leq \$ 75,000 \\ \$ 17,100+0.4(y-\$ 75,000) & \text { if } \$ 75,000<y \leq \$ 150,000 \\ \$ 47,100+0.45(y-\$ 150,000) & \text { if } y>\$ 150,000,\end{cases}
$$

where $y$ is taxable income.

\subsection{Market structure}

The economy is assumed to be small in the sense that all agents in the economy take the world prices for internationally traded goods and the world interest rate on bonds as given. We normalize the world price to 1 and assume that the world (and domestic) interest rate is $r=5 \%$. The budget constraint for the small open economy may be expressed in steady state form as $0=r F A+T B$, where $F A$ and $T B$ are the net holding of foreign assets and trade balance respectively. The right hand side is the current account balance consisting of net interest receipts plus the balance of trade (value of exports minus the value of imports) and the left hand side is net capital flows, which are zero in steady state. In a steady state, the stock of foreign asset holding is constant and so $0=r F A+T B$, meaning that there is a current account balance with interest on

\footnotetext{
${ }^{7}$ More details on the data and estimation methods provided in the Technical Appendix available at Chung Tran's website.
} 
foreign assets (if $F A<0$ ) matched by a positive trade balance. The Australian trade balance in the last 15 years is about -1.3 percent of GDP. Using this fact in the context of a steady state, the net foreign asset is calculated as $F A=T B / r=0.013 \times Y / r>0$, which implies that Australia is a net investor in the world capital market. However, data on Australia's international position reveals the opposite - Australia is a net borrower from the world capital market. Since our benchmark economy is in steady state, it cannot accommodate both facts. In the model, we assume that Australia is a net borrower with $19 \%$ of total national assets being foreign-owned.

\subsection{Benchmark model performance}

In this section, we present the calibration result of the benchmark model and discuss how our model solution matches data describing the Australian economy. ${ }^{8}$ We summarize our calibration results in Fig. 1.

Asset holdings. Panel 1 of Fig. 1 shows the life-cycle profile of asset holdings by age, relative to age of 50. Our model is able to generate a hump-shaped pattern of asset holdings over the life-cycle that broadly matches data drawn from the HILDA panel data set. ${ }^{9}$ In our life-cycle model with income uncertainty and incomplete markets, individuals accumulate assets in early stages of a life cycle. However, individuals draw down savings faster in the model than observed in the data because they do not have other motives to save, such as for bequests or to accommodate other life cycle shocks. De Nardi et al. (2010), for example, show that bequest motives and health expenditure shocks are the main determinants of savings behavior of elderly American households. Also, we abstract from compulsory retirement savings via superannuation and from housing in our model. Incorporating these features would potentially improve the match between model and data generated asset profiles.

Labor force participation and work hours: Panels 2 and 3 of Fig. 1 present work hours and labor force participation rates over the life cycle. Our model can match the observed life cycle pattern of labor market behavior and does a good job of capturing life cycle trends in labor force participate rates. However, it generates more young individuals participating in the labor force in early stages of the life cycle. This is primarily due to the assumption of no bequest motive. Since agents are born with no assets our model, there is very little wealth effect on labor supply decisions at young ages. Consequently, the new born agents optimally choose to work to maintain consumption. However, as agents accumulate more assets in middle and older ages, our model captures the labor force participation rates quite well. Agents between ages 20 and 40 years, on average, supply around 30 hours of work per week. Starting from the early 50s, agents decrease work hours and when they reach 70 years of age there is virtually no labor supplied.

Labor earnings and consumption. Panel 4 of Fig. 1 shows the life-cycle profile of labor earnings by age. The model captures such observed life cycle pattern of labor earnings from HILDA data. In addition, our model generates the hump-shaped pattern of consumption over the life cycle. The model results also match the faction of retirees in the means-tested pension program at 65.

In short, our benchmark model economy is able to match some key features of the Australian economy. In next section, we apply our model to quantitatively explore the implications of a means tested pension for macroeconomic variables and household welfare.

\section{Policy experiments and results}

In this section, we examine how the salient features of a means tested pension influence individuals' incentives to work and save, macroeconomic aggregates and welfare. Our main concern is with the choice of values of the maximum pension benefit $\left(P^{\max }\right)$ and the income test taper rate $\left(\omega_{y}\right)$. In order to understand how a choice of these two policy instruments influence individuals' inter-temporal allocations of consumption and hours of work, the insurance-incentive trade-off and welfare consequences, we implement a number of hypothetical policy reforms. ${ }^{10}$

\subsection{The effects of taper rates}

We first consider the implications of alterations in the taper rate for the income test, keeping the maximum pension level unchanged. We start our analysis with the benchmark economy and vary the taper rate, $\omega_{y}$, over the interval between 0 and 1. Any financial discrepancy between the government's consolidated tax revenues and expenditures are financed by a higher or lower income tax rate.

\footnotetext{
${ }^{8}$ We follow the algorithm in Auerbach and Kotlikoff (1987) to solve the model. The general procedure to solve for general equilibrium is described in the Appendix.

9 Although HILDA is a longitudinal survey, not all questions are asked in every wave. Since waves 2 and 6 collect information on household assets, we construct the age profiles of asset holdings based on data from these two waves.

${ }^{10}$ While the Australian system, as modeled here, has two tests - the income and asset tests - each of which has three such parameters, our policy experiments will simplify the analysis by concentrating on the design of the income test alone, keeping the assets test unchanged. In addition, we would like to emphasize that this part of the paper explores quantitatively a range of policy parameter values in which a means-tested pension program is preferred to a universal pension program. We therefore focus on a steady state analysis, similar to Imrohoroglu et al. (1995) and Fuster et al. (2003). Of course, the final welfare consequences of social security reform depend upon transitional costs and other factors.
} 

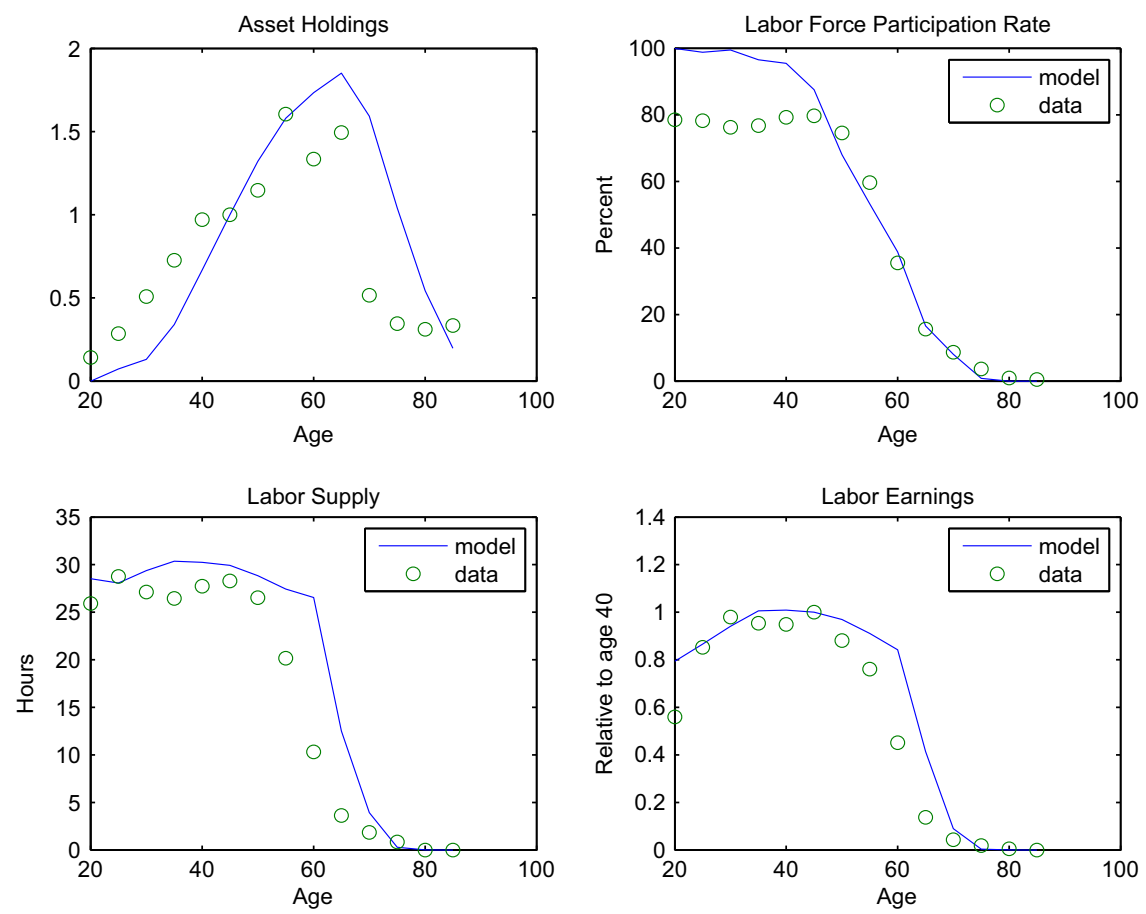

Fig. 1. The benchmark model and the data.

Table 3

Income tests and public pension participation rates by skill types at 65 .

\begin{tabular}{llll}
\hline \multirow{2}{*}{ Skill type } & \multicolumn{3}{l}{ Taper rate- $\omega_{y}$} \\
\cline { 2 - 4 } & {$[\mathbf{1}] \omega_{y}=0.4$} & {$[\mathbf{2}] \omega_{y}=0.0$} & {$[\mathbf{3}] \omega_{y}=1.0$} \\
\hline Low (\%) & 96.3 & 100.0 & 67.1 \\
Medium (\%) & 66.7 & 100.0 & 54.5 \\
High (\%) & 46.5 & 100.0 & 27.6 \\
All (\%) & 68.2 & 100.0 & 50.3 \\
\hline
\end{tabular}

Redistribution through extensive margin. As argued, inclusion of means testing in pension programs allows governments to have more flexibility to control the condition for receiving benefits. To understand how the presence of taper rate allows the government to target low income retirees we start from the benchmark economy with a means-tested pension system (the benchmark economy with $\omega_{y}=0.4$ labeled [1]) and consider two extreme policies: [2] one with the taper rate eliminated $\left(\omega_{y}=0.0\right)$ and [3] one with the taper rate increased to $1\left(\omega_{y}=1.0\right)$. We report fractions of individuals receiving public pension benefits at age of 65 according to their skill types in Table 3.

Means testing directs benefits to those retirees most in need. As seen in column [1] of Table 3 in the benchmark economy, about 96 percent of low skill individuals receive pension benefits at age of 65, while less than a half, about 46.5 percent, of high skill individuals receive the pension. In an economy in which the government removes the income test (see column [2] of Table 3), all individuals regardless of skill type are entitled to receive the age pension upon reaching the entitlement age. This is a universal pension system where all individuals have access to public pension. The extensive margin is eliminated. Conversely, when the government increases the taper rate to 1.0, the fraction of retirees receiving benefits drops significantly to around 50 percent (column [3] of Table 3).

More specifically, we consider the elderly population according to three states of the public pension: no pension, partial pension benefits and full or maximum pension benefits. Fig. 2 presents the effects of the taper rate on the pension status of the elderly population. As seen in panels 1 and 2 of Fig. 2, all individuals, who are 65 and older and regardless of their skill, are entitle to received full pension benefits when there is no testing in play $\left(\omega_{y}=0\right)$. However, when the government introduces the taper rate of $\omega_{y}=0.4$, only a fraction of the elderly individuals, mainly low skill ones, receive the pension at 65. Elderly individuals with high skill receive the public pension very late in the life cycle as it takes more time to decumulate their wealth to meet the test thresholds (panel 4 of Fig. 2). 

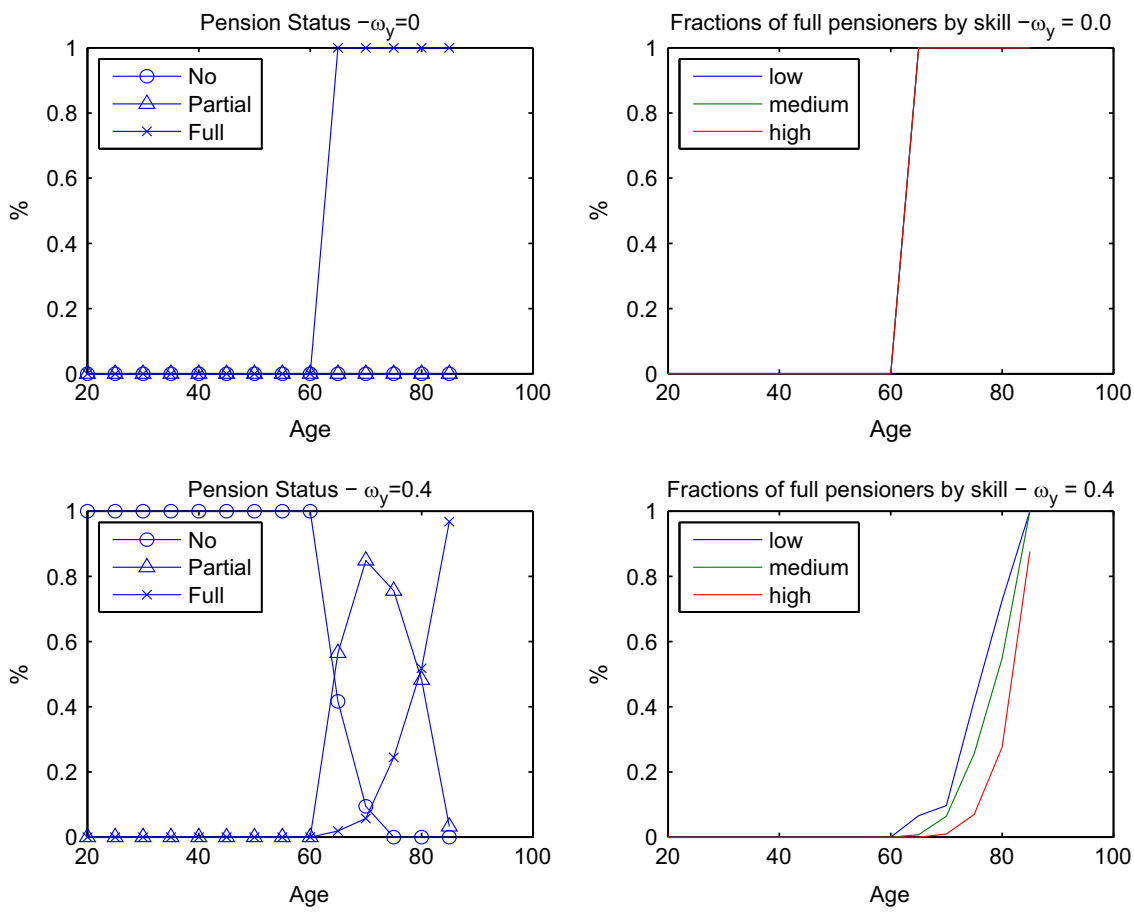

Fig. 2. Means testing and pension status.

Thus, the government can use taper rates to control the number of pensioners (extensive margin). This allows the government to have another margin to redistribute income toward low income retirees.

Incentives to save and work. We now study the effects of taper rates on individuals' incentives over the life-cycle. We consider behavioral changes between two economies: [1] the benchmark economy with a means-tested pension system $\left(\omega_{y}=0.4\right)$ and [2] an economy in which income test is removed $\left(\omega_{y}=0\right)$, i.e., a universal pension system. We present changes in the life-cycle behavior of savings and labor supply in Fig. 3.

Panels 1 and 2 of Fig. 2 depict the asset holdings across the life-cycle with and without the income test. Interestingly, while a higher taper rate increases savings before retirement it causes an abrupt decrease in retirees' asset holdings. This indicates that the presence of the extensive margin $\left(\omega_{y}>0\right)$ creates an uncertain situation in which workers are not sure about receiving pension benefits. This extensive margin effect induces workers to save more for their retirement. However, retirees decumulate their assets faster in the late stages of the life cycle, when the taper rate is present. This implies that, once individuals pass their retirement age, they optimally save less to maximize their pension benefits. The taper rate has two opposing effects on savings incentives over the life cycle: a positive one before retirement and a negative one after that. The lifetime savings effect depends how these two forces play out. In this case, it appears that the former dominates the latter with lifetime savings increasing. Overall, the introduction of the taper rate of $\omega_{y}=0.4$ creates a moderate increase in asset holdings.

Panels 3 and 4 of Fig. 3 present how individuals adjust the intensive (work hours) and extensive (timing of retirement) of the labor supply over the life-cycle. The presence of the taper rate induces individuals to supply slightly more labor before age of 65 , but significantly discourages them from supplying more hours after that (see panel 3 of Fig. 2). There are substantial drops in work hours after age of 65. In addition, the presence of means-testing discourages individuals from participating in the labor force. As seen in panel 4 of Fig. 2, when the taper rate is introduced individuals withdraw earlier from the labor market starting from their $40 \mathrm{~s}$ in order to increase their probabilities of becoming a pensioner. Yet, the introduction of the taper rate has a negative effect on the extensive margin of labor supply and two opposing effects on the intensive margin of labor supply over the life cycle. The final effect on aggregate labor supply depends on how these forces play out.

Hence, uncertainty in receiving pension benefits combines with high effective tax rates in retirement ages to distort individuals' inter-temporal allocations of resources over the life cycle. ${ }^{11}$

\footnotetext{
11 Previous empirical studies find that earnings tests significantly affect savings and labor supply decisions in older ages, especially around the mandatory age from which individuals are eligible for retirement benefits. Neumark and Powers (1998) and Neumark and Powers (2000) estimate the effects of means-tested Supplemental Security Income for old age individuals in the U.S.A. and find that these retirement benefits reduce savings and labor supply of those likely to participate in the program when approaching retirement age. There are also a number of studies exploring the effects of laborearning tests on early retirement and the elderly's working hours in the U.K. Friedberg (2000) and Disney and Smith (2002) find that an abolition of the earning test induces older male workers to work more hours. In addition, previous analyses of the effects of means-tested, non-pension benefits (e.g., see Hubbard et al., 1995; Powers, 1998; Gruber and Yelowitz, 1999; Heer, 2002; Chou et al., 2004) also found that the asset test reduces saving incentives of low income households.
} 

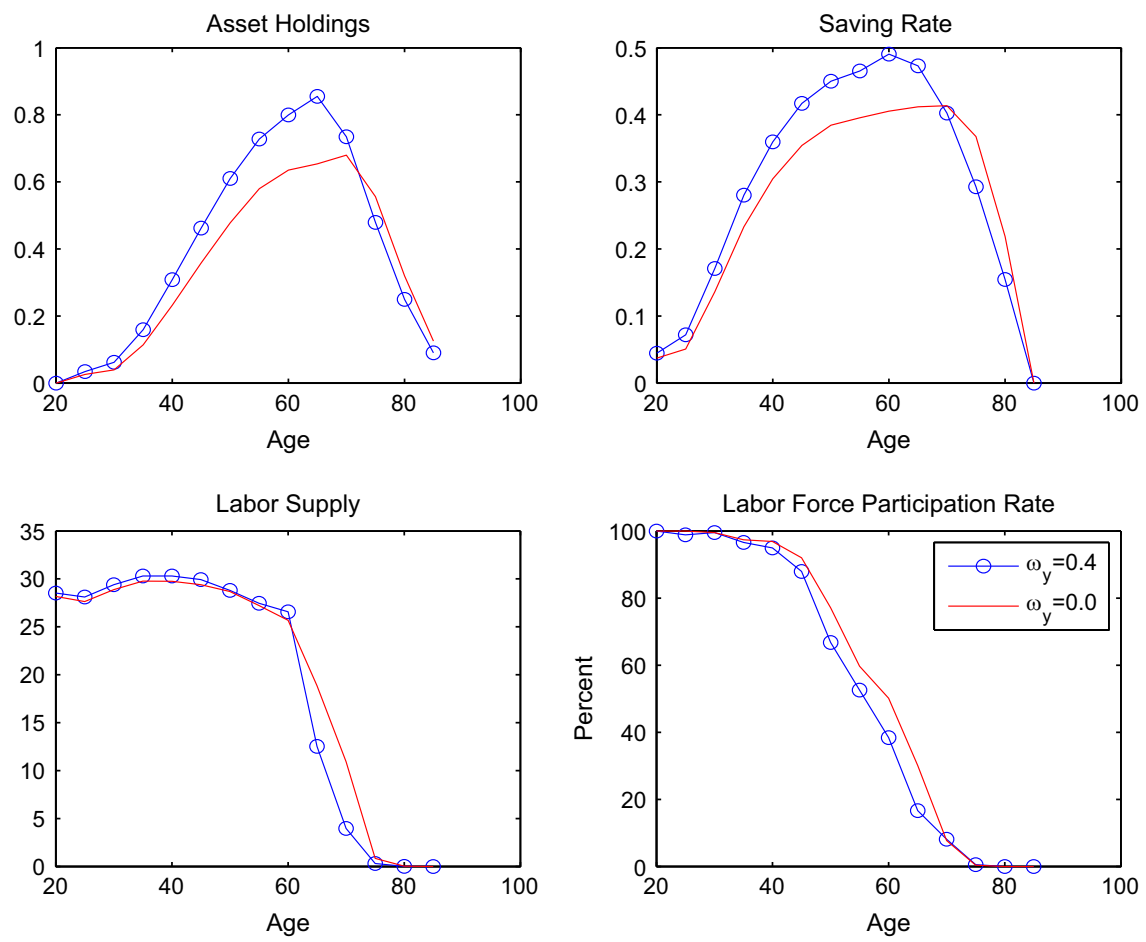

Fig. 3. Taper rate and incentives to save and to work.

Table 4

Aggregate and welfare effects when adjusting the taper rate. The values of capital, labor and output in the benchmark model are normalized to 100 and so the entries in the table show these variables relative to 100 for the benchmark model. We format the benchmark values in italics.

\begin{tabular}{ccccl}
\hline Taper rates $\left(\omega_{y}\right)$ & Capital & Labor & Output & CEV(\%) \\
\hline \hline 0.0 & 83.51 & 98.40 & 93.17 & -6.573 \\
0.1 & 90.98 & 99.16 & 96.36 & -3.523 \\
0.2 & 97.33 & 99.71 & 98.98 & -0.837 \\
$\mathbf{0 . 3}$ & 99.69 & 99.91 & 99.84 & $\mathbf{0 . 0 0 6}$ \\
\hline 0.4 & 100.00 & 100.00 & 100.00 & 0.000 \\
\hline 0.5 & 99.66 & 100.12 & 99.84 & -0.234 \\
0.6 & 98.22 & 100.11 & 99.29 & -0.920 \\
0.7 & 96.82 & 100.10 & 98.74 & -1.603 \\
0.8 & 96.33 & 100.09 & 98.63 & -1.845 \\
0.9 & 94.72 & 100.05 & 98.00 & -2.584 \\
1.0 & 94.46 & 100.03 & 97.96 & -2.711 \\
\hline
\end{tabular}

Macro-aggregates. We consider a wider range of alternative means test parameters and report the results of these experiments in Table 4. Column 1 specifies the various values of the income taper rate. Columns 2-5 present the values of aggregate variables including domestic asset, labor, output and expected utility. Again, we normalized the values of aggregate variables (but not utility) in the benchmark economy $\left(\omega_{y}=0.4\right)$ to 100 , which are shown in italics in row 5 , and report those in alternative economies relative to the benchmark.

We find that changing taper rates results in non-linear effects on macroeconomic aggregates. When the government raises the taper rate from 0.4 to 1 , there is a decrease in aggregate stock of capital and effective labor. This suggests that the economy is in a region in which the adverse effects of the taper rate as an implicit tax dominate the effects of the taper rate via the extensive margin. Raising the taper rate therefore discourages individuals from saving more or working longer, as they face a higher effective marginal income tax rate on labor and interest earnings at higher ages. The increase in the taper rate therefore induces individuals to save more or work extra hours. This result is consistent with empirical evidence documented in previous empirical studies, such as Neumark and Powers (1998), Neumark and Powers (2000), Disney and Smith (2002) and Friedberg (2000). This result is also consistent with Sefton et al. (2008), who analyze a calibrated multiperiod overlapping generations model of the U.K. However, when the government raises the taper rate from 0.0 to 0.4 , there 
is an increase in capital stock and labor supply. This implies that the positive effect of taper rates via the extensive margin dominates the negative effects resulting from higher implicit tax rates. The hump-shaped pattern of capital stock and labor supply over a range of parameter values of taper rates could be explained by the dynamic interaction between the extensive and intensive margins described in our analytical results in Section 2 further above. Overall, we find that removing the income test results in a lower capital stock and labor supply, causing output to drop by about 7 percent.

Welfare: In order to assess the welfare effects of a policy reform on different cohorts we use the ex-ante expected utility of an unborn agent before the productivity level is revealed. Welfare gain (or loss) is expressed in terms of consumption equivalent variation (CEV). It measures a percentage change in consumption across all possible states of the economy in the initial steady state that makes the household indifferent between the two economies with and without the policy change. A positive number implies that households are better off with policy change and a negative number implies that they prefer to stay in the benchmark economy with $\omega_{y}=0.4$.

As already argued, the introduction of a taper rate to the pension design results in two opposing effects. First, since the resulting means test targets lower income agents (extensive margin), it mitigates self-insurance disincentives, lowers the deadweight loss of tax financing, and strengthens intra- and inter-generational risk-sharing. Second, it creates economic distortions as it imposes a higher implicit income tax (by the amount of the taper rate) on savings and labor incomes of pensioners. When the former effect is dominant, the welfare effects are positive; otherwise, the welfare effects will be negative. In this experiment, we examine how these two effects interplay.

We first consider whether the current means tested pension system in Australia would deliver a more favorable outcome than a universal pension system like the one in the U.S. We compare the benchmark economy $\left(\omega_{y}=0.4\right)$ and the economy with no means testing $\left(\omega_{y}=0\right)$. From column 5 of Table 4 , we find that welfare is lower in the economy with a universal pension system $\left(\omega_{y}=0\right)$ than in the benchmark economy. The long-run welfare effect is negative, 6.6 percent in consumption equivalence, meaning that newly born agents would prefer to live in the benchmark economy. We conclude that the means tested pension system in the benchmark economy is socially preferred to the universal pension system.

Another way to understand the welfare effects is by examining the welfare effects across skill types. To this end, we compute the consumption equivalent variation (CEV), conditioning on skill type at birth. In Table 5, we present compensating variation in consumption for each skill type and for all types together when varying the taper rate between 0 and 1. Notice that, to ease our welfare comparison, we compute CEV between economies with means testing $\left(\omega_{y}>0\right)$ and the economy with no means testing $\left(\omega_{y}=0\right)$. If the CEV number is positive, it means that the household is better off when the taper rate is introduced.

Looking at the whole range for the taper rate, we observe that the introduction of, and increase in, a small taper rate at first improves welfare for the household, reaches a maximum, and then decreases welfare at higher taper rates. Starting from the benchmark taper rate, $\omega_{y}=0.4$, the welfare gains for a household decreases as taper rates are increased, implying that the adverse incentive effects of the more stringent income test dominant the insurance effects in this policy parameter range. On other hand, however, we find the opposite outcome as the taper rate is reduced from 0.4 to 0 (see column 2 of Table 5). More specifically, comparing our benchmark economy where the taper rate is set at 40 percent, i.e., $\omega_{y}=0.4$, to the economy with no means testing, we find that the average household in an economy with universal pension would be willing to give up 7.03 percent of consumption equivalence in order to raise the taper rate from 0 to 40 percent. Overall, we find that the welfare effects have a hump-shaped pattern, a result consistent with that found for our numerical example of the simple model in Section 2.

This non-linear pattern of welfare effects of changes in the income taper rate clearly indicates a trade-off between the insurance and incentive aspects of means testing. When the economy is in a region where the insurance effects are dominant, increases in the taper rate induce more self-insurance by working longer hours and increasing saving, which, in

Table 5

The welfare effects of taper rates by skill types. Note that welfare gains/losses are measured in terms of consumption equivalent variation. If the number is positive, it means that the household is better off when taper rate is introduced.

\begin{tabular}{clrrr}
\hline & \multicolumn{4}{c}{ CEV(\%) by Skill Types } \\
Taper rates $\left(\omega_{y}\right)$ & All types & Low & Medium & High \\
\hline \hline 0.0 & 0.00 & 0.00 & 0.00 & 0.00 \\
0.1 & 3.26 & 3.62 & 3.22 & 2.73 \\
0.2 & 6.18 & 6.81 & 6.03 & 5.13 \\
$\mathbf{0 . 3}$ & $\mathbf{7 . 0 4}$ & 7.85 & 6.91 & 5.87 \\
\hline 0.4 & 7.03 & 7.87 & 6.92 & 5.81 \\
\hline 0.5 & 6.78 & 7.63 & 6.67 & 5.57 \\
0.6 & 6.05 & 6.84 & 5.92 & 4.95 \\
0.7 & 5.31 & 6.07 & 5.22 & 4.32 \\
0.8 & 5.06 & 5.79 & 4.96 & 4.10 \\
0.9 & 4.27 & 4.92 & 4.18 & 3.43 \\
1.0 & 4.13 & 4.77 & 4.04 & 3.34 \\
\hline
\end{tabular}


turn, lead to efficiency gains and a positive welfare outcome. However, when the taper rate becomes bigger, distortions arising from having higher effective marginal tax rates become more severe, which, in turn, reduce savings and labor supply. Aggregate capital, labor supply and income decrease and welfare subsequently decreases.

The point at which expected utility reaches a maximum is around $\omega_{y}=0.3$. This indicates that the introduction of means testing (via a taper rate) is socially desirable in our model, conditioning the pre-existence of a pension system with the benchmark level of the maximum pension benefit. Sefton and van de Ven (2009) conduct a welfare analysis in a partial equilibrium model of the U.K. pension system and also find that means tested pensions are socially desirable. Our analysis of the Australian pension system in a general equilibrium framework also reaches a similar conclusion. This suggests that the conclusions of Sefton and van de Ven obtained with a partial equilibrium model might well be confirmed for the U.K. when accounting for dynamic general equilibrium adjustments.

Columns 3, 4 and 5 of Table 5 present the welfare effects across different skill types. Interestingly, we find welfare gains for all skill types. This indicates that both low and high skill individuals benefit from aggregate efficiency gains after introducing means testing. Notably, and as expected, low skill individuals experience relatively higher welfare gains. Considering the case when the taper rate is $\omega_{y}=0.4$, the welfare gain for low skill individuals is 7.87 percent in consumption equivalence; meanwhile, the welfare gain for high skill individuals is 5.81 percent in consumption equivalence. The positive welfare result for the low skill type is not surprising because these agents benefit relatively more from a means-tested pension system. The underlying mechanism behind the positive welfare effect for the low skill type is mainly from the redistribution effects through extensive margin. As seen from Fig. 2 and Table 3, the presence of taper rates directs pension benefits towards low skill retirees via the extensive margin. This subsequently redistributes wealth to a relatively larger fraction of low skill individuals, who are more likely to be eligible for a means-tested pension program. On other hand, the main logic behind the welfare gains for the medium and high skill types is the efficiency gains from mitigating fiscal distortions and accumulating more capital and labor. Indeed, the presence of taper rates mitigates the fiscal distortions caused by a public pension program by reducing the size of a pension program. In addition, means testing effectively improves incentives to save and to work, which then results in more stock of labor and capital in production as stated in Table 4. The general equilibrium channel subsequently spreads these aggregate efficiency gains to all agents, including medium and high skill individuals. Thus, all agent types prefer means-tested pension to universal pension in our framework.

\subsection{The effects of maximum benefits}

In a general equilibrium model, changes in the levels of maximum pension benefits affect not only the generosity of pension benefits (intensive margin) but also the number of pensioners in the economy (extensive margin). However, the effects via the former tend to be strong. To understand the effects of the maximum benefits, we simulate a number of alternative model economies in which we vary the levels of the maximum pension benefits, while keeping the taper rate unchanged at its benchmark level.

Technically, we index the maximum pension benefit in an alternative economy to that in the benchmark economy as $P^{\max }(\varphi)=\varphi P^{\max }$ benchmark , where $P^{\max }(\varphi)$ denotes the maximum pension benefits in the economy after the reform and $\varphi \geq 0$ is a parameter. Note that there are several special cases: when $\varphi=0$ the government closes the pension program, and when $\varphi=1$ it is the benchmark economy. In our experiments, setting $\varphi<1$ implies a lower maximum pension benefit than in the benchmark economy, while $\varphi>1$ implies a higher maximum pension benefit. Any financial discrepancy between the government's consolidated tax revenues and expenditures are financed by a higher or lower income tax rate.

We report the main macro-aggregate and welfare effects of these experiments in Table 6. The first column specifies the maximum pension benefits relative to the maximum pension in the benchmark economy. Note that we normalized capital, labor, output (but not expected utility) in the benchmark model $(\varphi=1)$ to 100 and so the entries in the Table show these variables relative to 100 for the benchmark model. We format the benchmark values in italics in Table 6 .

In all the experiments reported in Table 6, we consistently find that capital stock, labor supply and output monotonically increase as the government decreases the generosity of pension benefits. This indicates that public pension programs result in adverse effects on individuals' incentives to save and work, thus crowding out savings, labor supply and output. Conversely, cutting the generosity of a public pension program improves efficiency and hence income. We also run the extreme experiment in which the government closes down the public pension program $(\varphi=0)$, shown by the bolded row in Table 6 . We find that when the public pension program is completely removed $(\varphi=0)$, efficiency gains from completely removing economic distortions of public pensions on savings and labor supply lead to the highest attainable income. These large crowding out effects on savings found in our experiments are primarily due to our small open economy model assumption. Since the domestic interest rate is equal to the world interest rate, which is assumed constant, general equilibrium interest rate adjustments are removed.

We now turn our attention to the welfare effects. As established in the previous literature, a social security system is often justified as a mechanism for sharing longevity and income risks (social insurance) across households and generations, which potentially improves welfare when markets imperfections are present. On other hand, however, social security systems are often criticized as being detrimental to capital accumulation, labor supply and growth because they distort savings and labor supply decisions (through adverse incentives), resulting in efficiency and welfare losses. The welfare outcomes of a social security system depends how the system trades off the insurance effect against the incentive effect. 
Table 6

Aggregate effects when adjusting maximum pension benefits. Note that we keep the taper rate unchanged at the benchmark level (0.4). The values of capital, labor and output in the benchmark model are normalized to 100 and so the entries in the table show these variables relative to 100 for the benchmark model. CEV is calculated for a new born agent at age 20 using the benchmark model as a base. We format the benchmark values in italics.

\begin{tabular}{cclll|}
\hline$P^{\max }(\varphi)=\varphi P^{\max , \text { benchmark }}$ & Capital & Labor & \multirow{2}{*}{ Output } & \multicolumn{2}{c}{ CEV $(\%)$} \\
$\varphi$ & & & \\
\hline \hline $\mathbf{0 . 0 0}$ & $\mathbf{2 4 7 . 7}$ & $\mathbf{1 0 4 . 2}$ & $\mathbf{1 5 0 . 1}$ & $\mathbf{4 1 . 6 1}$ \\
0.10 & 239.7 & 103.9 & 148.0 & 39.83 \\
0.25 & 219.3 & 103.5 & 142.3 & 35.07 \\
0.50 & 173.8 & 102.4 & 128.3 & 23.49 \\
0.75 & 133.8 & 101.3 & 113.9 & 11.84 \\
\hline 1.00 & 100.0 & 100.0 & 100.0 & 0.00 \\
\hline 1.25 & 72.1 & 98.79 & 86.34 & -11.92 \\
1.50 & 53.6 & 96.48 & 75.69 & -21.45 \\
\hline
\end{tabular}

In our quantitative experimental results reported in column 5 of Table 6 , we find that decreasing the generosity of pension benefits (reducing $\varphi$ ) always leads to increases in the expected utilities of individuals so that expected utility is maximized when the public pension ceases $(\varphi=0)$. This indicates that the adverse effects on incentives always dominate the insurance effect even when means testing is present. It seems that means testing strengthens risk-sharing and incentives via extensive margin effects, but fails to overturn the negative intensive margin effects.

We conclude that a means tested pension is not socially desirable in our dynamic general equilibrium economy as expected utility is highest in an economy with no public pension. This is perhaps not surprising as we learnt from previous studies that general equilibrium adjustments magnify the crowding out effects of social security systems without means testing and that negative welfare outcomes are likely. Indeed, the PAYG social security literature using a dynamic general equilibrium model consistently finds negative welfare effects because the adverse effects on incentives dominate the insurance effect (Auerbach and Kotlikoff, 1987; Imrohoroglu et al., 1995), leading to the recommendation that governments privatize their PAYG social security systems. In that sense, our finding for an old-age pension scheme with means testing is consistent with the previous results in the literature of general equilibrium analysis of social security without means testing.

\subsection{Interactions between maximum benefits and taper rate}

We now turn our attention to interactions between maximum pension benefits and taper rates, and derive implications for the insurance-incentive trade-off and welfare. We numerically characterize two steady states economies with two different levels of the maximum pension benefits: low $\varphi=0.5$ and high $\varphi=1.5$. In each alternative economy, the government keeps the maximum pension benefit unchanged and the government varies the taper rate between 0 and 1 .

We report the effects of alternative taper rates and maximum pension benefits in the design of means testing of the oldage pension on the aggregate capital stock and labor supply in Table 7.

Macro-aggregates. We find that the effects of changes in the taper rates on the aggregate capital stock and labor supply vary significantly across the economies. In the economy where the level of maximum pension benefits is relatively low, the taper rate that maximizes the capital stock and labor supply is 1 , which is much higher than in the benchmark economy. On other hand, in the economy where the level of maximum pension benefits is relatively high, the taper rate that maximize the levels of aggregate capital and labor is around 0.3. This indicates that the effects of means testing on incentives to work and to save are dependent of the levels of maximum pension benefits. When the levels of maximum pension benefits are relatively low, tightening the taper rate leads to an increase in the capital stock and labor supply. The intuition for this result can be explained by the prediction in our simple model. That is, when the pension benefits $P^{\mathrm{max}}$ are relatively less generous the positive extensive margin effect is positive and always dominates the negative intensive margin effects. On other hand, in the economy where the levels of maximum pension benefits are relatively generous (benchmark or high) there is a trade-off between two opposing forces. The positive extensive margin effect tends to be a dominant force when the rate is small, but loses ground to the negative intensive margin effects as the taper rate becomes sufficiently high (0.4 or above in the benchmark economy). This result confirms that the existence of the extensive margin embedded in a means tested pension system potentially mitigates the adverse intensive margin effects on savings.

Welfare: We now analyze the welfare outcome in which the interactions between the insurance and incentive effects are taken into account. Our results for the effect of these different policy settings upon expected utility are summarized in Table 8. We find that the welfare effects of varying the taper rate are different across the three economies and, hence, dependent upon the levels of the maximum pension benefit. In the first economy where the maximum pension benefits are relatively less generous (Low), increases in the taper rate lead to monotone increases in capital stock, labor supply, national income and, therefore, expected utility. This implies that the effects of higher taper rates in mitigating self-insurance disincentives and strengthening risk-sharing are always dominant so that the welfare effects are always positive. The optimal 
Table 7

Aggregate capital stock and labor supply when adjusting tapter rates in three different economies: low, benchmark and high maximum pension benefits.

\begin{tabular}{|c|c|c|c|c|c|c|}
\hline \multirow[b]{2}{*}{ Taper rate } & \multicolumn{3}{|c|}{ Capital } & \multicolumn{3}{|c|}{ Labor } \\
\hline & $\varphi=.5$ & Bench. $(\varphi=1)$ & $\varphi=1.5$ & $\varphi=.5$ & Bench. $(\varphi=1)$ & $\varphi=1.5$ \\
\hline 0.0 & 86.21 & 83.51 & 83.43 & 98.65 & 98.40 & 98.34 \\
\hline 0.1 & 93.64 & 90.98 & 89.50 & 99.51 & 99.16 & 98.91 \\
\hline 0.2 & 97.63 & 97.33 & 89.91 & 99.91 & 99.71 & 99.61 \\
\hline 0.3 & 100.08 & 99.69 & 97.01 & 99.95 & 99.91 & 99.79 \\
\hline 0.4 & 100.00 & 100.00 & 100.00 & 100.00 & 100.00 & 100.00 \\
\hline 0.5 & 100.19 & 99.66 & 97.09 & 100.10 & 100.12 & 99.97 \\
\hline 0.6 & 102.72 & 98.22 & 93.93 & 100.15 & 100.11 & 99.88 \\
\hline 0.7 & 103.40 & 96.82 & 91.24 & 100.16 & 100.11 & 99.81 \\
\hline 0.8 & 103.86 & 96.33 & 88.24 & 100.18 & 100.10 & 99.73 \\
\hline 0.9 & 104.91 & 94.72 & 87.00 & 100.20 & 100.05 & 99.84 \\
\hline 1.0 & 105.73 & 94.46 & 85.73 & 100.23 & 100.03 & 99.79 \\
\hline
\end{tabular}

Table 8

The welfare effects when adjusting taper rates in different economies. Note that welfare gains/losses are measured in terms of compensating variation in consumption that is necessary to make an agent indifferent between keeping taper rate and eliminating taper rate. If the number is positive, it means that the household is better off when taper rate is introduced.

\begin{tabular}{cccc}
\hline & \multicolumn{3}{c}{ CEV (\%) } \\
\cline { 2 - 4 } Taper rate & $\varphi=.5$ & Bench. $\varphi=1.0$ & $\varphi=1.5$ \\
\hline \hline 0.0 & 0.00 & 0.00 & 0.00 \\
0.1 & 3.39 & 3.26 & 3.15 \\
0.2 & 5.01 & 6.18 & 5.12 \\
0.3 & 5.63 & $\mathbf{7 . 0 4}$ & 6.38 \\
\cline { 2 - 4 } 0.4 & 5.73 & 7.03 & $\mathbf{7 . 6 2}$ \\
0.5 & 6.62 & 6.78 & 6.21 \\
0.6 & 6.78 & 6.05 & 4.53 \\
0.7 & 7.02 & 5.31 & 3.37 \\
0.8 & 7.24 & 5.06 & 1.96 \\
0.9 & 7.64 & 4.27 & 1.32 \\
1.0 & $\mathbf{7 . 9 7}$ & 4.13 & 0.43 \\
\hline
\end{tabular}

taper rate in this economy is $\omega_{y}=1$. There is no clear trade-off between insurance and incentive effects as the taper rate increases. However, as pointed in the previous analysis, the positive extensive margin effects tend to be a dominant force.

In the third economy where the maximum pension benefits are assumed to be $150 \%$ more generous than in the benchmark economy (High), we again find a hump-shaped pattern of welfare effects. This is indicative of the two opposing effects of means testing at work: mitigating self-insurance disincentives and strengthening risk-sharing versus distortions of higher effective marginal income tax rates of the higher taper rate. When the former is dominant the welfare effects are positive; otherwise, they are negative. The insurance and incentive effects are evenly balanced around $\omega_{y}=0.3$, which is the optimal taper rate in this economy. Note that the taper rate that delivers the best welfare outcome is not necessarily the one that results in highest levels of capital stock, labor supply and output. The difference is partly due to the fact that means testing strengthens the social insurance role of the pension system.

To enable a more detailed examination of the welfare and macroeconomic implications of alternative pension design parameters, we simulate a number of alternative economies for a wider range of maximum pension benefits. We find that the level of expected utility is greatest when the taper rate is unity for old-age pension replacement rates up to 0.6, indicating that it is optimal for pensioners to only receive the pension for incomes less than the income threshold. The optimal taper rate is 0.5 when the replacement rate is 0.75 , drops to 0.3 for replacement rates of unity and 1 , but increases to 0.4 when the replacement rate is 1.5. Thus, the optimal taper rate first falls and then increases as the pension becomes more generous. This indicates that the welfare effect of introducing and increasing an income test taper rate is nonlinear and dependent of the level of the maximum pension benefit.

In summary, we find from these Tables that the interaction between these two policy instruments is important as it has different implications for individuals' inter-temporal allocation of resources, macroeconomic aggregates and welfare. The interaction between the maximum pension benefit and the taper rate magnifies the disincentive effects of the taper rate as an implicit tax on life-cycle savings and labor supply. These results point out the importance of accounting for the interaction between these two pension policy instruments and of analyzing the economic mechanisms that explain these nonlinear effects. 


\section{Conclusion}

Inclusion of means testing in the pension benefit formula allows governments to have additional policy instruments to affect the number of public pensioners (extensive margin) and the benefit level (intensive margin). The former is aimed at strengthening risk sharing across individuals and generations and to mitigate the adverse effects of self-insurance incentives. In this paper, we analyzed the welfare implications of these salient features of old-age pension design for the trade-off between insurance and incentive effects. We find that the extensive margin strengthens the insurance effect but introduces two opposing effects on incentives, and that the magnitude of the positive extensive margin effect depends on relative strength of the intensive margin. The final welfare outcome depends how two opposing effects on incentives play out in the economy.

We investigate these trade-offs in a dynamic general equilibrium model with heterogeneous agents that is calibrated to the Australian economy. We find that the introduction of a taper rate leads to positive welfare outcomes and that the pattern of welfare effects varies, depending on the level of maximum pension benefits. More specifically, when the maximum pension benefit is relatively less generous, increases in taper rates always lead to a welfare gain as the insurance effect and the positive incentive effect are always dominant. However, when the maximum pension benefits are relatively more generous, there is an optimal taper rate at which the insurance and positive incentive effects efficiently trade off with the negative incentive effects and at which expected utility is maximized. Importantly, our results reveal that the interactions between the levels of maximum pension benefits and taper rates are critical in forming the direction of the welfare effects.

Our results carry important policy implications. Countries that are interested in introducing means testing to their currently universal pension systems should take into account the potential interactions between the choice of taper rates and the choice of the levels of maximum pension benefit. Our results highlight the point that the effects of a higher taper rate on savings, labor supply and household welfare are nonlinearly dependent on the level of the maximum pension benefit.

\section{Appendix A}

\section{A.1. Simple model: solving the model}

We provide a solution for a model in which savings is incorporated in the income test formula and the government finances its pension program via a tax on the labor income of the young.

Household: The individual agent's optimization problem is

$$
\max _{c_{1}, c_{2}, s}\left\{u\left(c_{1}\right)+p E u\left(c_{2}\right) \text { st. } c_{1}+s=(1-\tau) w_{1} \text { and } c_{2}=w_{2}+(1+r) s+P\right\},
$$

where $P$ is the pension benefit defined as

$$
P= \begin{cases}P^{\max }-\omega\left[w_{2}+\xi r s\right] & \text { if } w_{2}+\xi r s<\bar{y}_{2} \\ 0 & \text { if } w_{2}+\xi r s \geqq \bar{y}_{2} .\end{cases}
$$

Let $y_{2}=w_{2}+r s$ be testable income and follows an uniform distribution. Assuming that $u(c)=-c^{2} / 2+\chi c$ is the functional form for individual preferences, the individual's first order necessary condition for optimality is

$$
-c_{1}+\chi=p E\left[u^{\prime}\left(c_{2}\right) \frac{\partial c_{2}}{\partial s}\right]
$$

where

$$
\begin{aligned}
& E\left[\left(c_{2}\right)^{-\sigma} \frac{\partial c_{2}}{\partial s}\right]=\int_{y_{2}^{\min }}^{y_{2}^{\max }}\left(-c_{2}+\chi\right)\left(\frac{\partial c_{2}}{\partial s}\right) f\left(y_{2}\right) d y_{2}=\chi-\int_{y_{2}^{\min }}^{y_{2}^{\max }} c_{2}\left(\frac{\partial c_{2}}{\partial s}\right) f\left(y_{2}\right) d y_{2}, \\
& f\left(y_{2}\right)=\frac{1}{w_{2}^{\max }}: \text { uniform } \sim\left[y_{2}^{\min }=r s, y_{2}^{\max }=r s+w_{2}^{\max }\right] .
\end{aligned}
$$

The individual's consumption in period 2 is

$$
c_{2}= \begin{cases}(1-\omega) w_{2}+[1+(1-\omega \xi) r] s+P^{\max } & \text { if } P>0 \\ w_{2}+(1+r) s & \text { if } P=0,\end{cases}
$$


and the first derivative with respect to saving is

$$
\frac{\partial c_{2}}{\partial s}= \begin{cases}1+(1-\omega \xi) r & \text { if } P>0 \\ (1+r) & \text { if } P=0\end{cases}
$$

Using this expression for consumption when old, expected marginal utility may be expressed as

$$
E\left[\left(c_{2}\right)^{-\sigma} \frac{\partial c_{2}}{\partial s}\right]=\chi-[1+(1-\omega \xi) r] p \int_{y_{2}^{\min }}^{\bar{y}_{2}}\left[(1-\omega) y_{2}+s+P^{\max }\right] f\left(y_{2}\right) d y_{2}-(1+r) p \int_{\bar{y}_{2}}^{y_{2}^{\max }}\left[y_{2}+s\right] f\left(y_{2}\right) d y_{2} .
$$

The individual's first order necessary condition becomes

$$
(1-\tau) w_{1}-s=\left\{\begin{array}{c}
{[1+(1-\omega \xi) r] p\left\{\int_{y_{2}^{\min }}^{\bar{y}_{2}}\left[(1-\omega) y_{2}+s+P^{\max }\right] \frac{1}{w_{2}^{\max }} d y_{2}\right\}} \\
+(1+r) p\left\{\int_{\bar{y}_{2}}^{y_{2}^{\max }}\left[y_{2}+s\right] \frac{1}{w_{2}^{\max }} d y_{2}\right\} .
\end{array}\right.
$$

Let $\widehat{w}_{2}=\bar{y}_{2}-r$ s denote the level of income endowment in period 2 that separates pensioners from non-pensioners, taking saving, $s$, as given. Noting that $d y_{2}=d w_{2}$, we obtain the expression

$$
\begin{aligned}
& (1-\tau) w_{1}-s=\left\{\begin{array}{c}
\frac{[1+(1-\omega \xi) r] p}{w_{2}^{\max }}\left\{\int_{0}^{\widehat{w}_{2}}\left[(1-\omega) w_{2}+[1+(1-\omega \xi) r] s+P^{\max }\right] d w_{2}\right\} \\
+\frac{(1+r) p}{w_{2}^{\max }}\left\{\int_{\widehat{w}_{2}}^{\bar{w}_{2}^{\max }}\left[w_{2}+(1+r) s\right] d w_{2}\right\}
\end{array}\right. \\
& =\left\{\begin{array}{l}
\frac{[1+(1-\omega \xi) r] p}{w_{2}^{\max }}\left[(1-\omega) \frac{\left(w_{2}\right)^{2}}{2}+\left([1+(1-\omega \xi) r] s+P^{\max }\right) w_{2}\right] \widehat{\mid}_{0}^{w_{2}} \\
+\left.\frac{(1+r) p}{w_{2}^{\max }}\left[\frac{\left(w_{2}\right)^{2}}{2}+(1+r) s w_{2}\right]\right|_{\widehat{w}_{2}} ^{w_{\max }},
\end{array}\right. \\
& =\left\{\begin{array}{l}
\frac{[1+(1-\omega \xi) r] p}{w_{2}^{\max }}\left\{\left[(1-\omega) \frac{\left(\widehat{w}_{2}\right)^{2}}{2}\right]+\left[[1+(1-\omega \xi) r] s+P^{\max }\right] \widehat{w}_{2}\right\} \\
+\frac{(1+r) p}{w_{2}^{\max }}\left[\frac{\left(w_{2}^{\max }\right)^{2}-\left(\widehat{w}_{2}\right)^{2}}{2}+(1+r) s\left(w_{2}^{\max }-\widehat{w}_{2}\right)\right],
\end{array}\right. \\
& =\left\{\begin{array}{c}
{[1+(1-\omega) r]^{2} p \frac{\widehat{w}_{2}}{w_{2}^{\max }} s+\frac{[1+(1-\omega) r] p}{w_{2}^{\max }}\left[(1-\omega) \frac{\left(\widehat{w}_{2}\right)^{2}}{2}+P^{\max } \widehat{w}_{2}\right]} \\
+(1+r)^{2} p \frac{w_{2}^{\max }-\widehat{w}_{2}}{w_{2}^{\max }} s+\frac{(1+r) p}{w_{2}^{\max }} \frac{\left(w_{2}^{\max }\right)^{2}-\left(\widehat{w}_{2}\right)^{2}}{2}
\end{array}\right.
\end{aligned}
$$

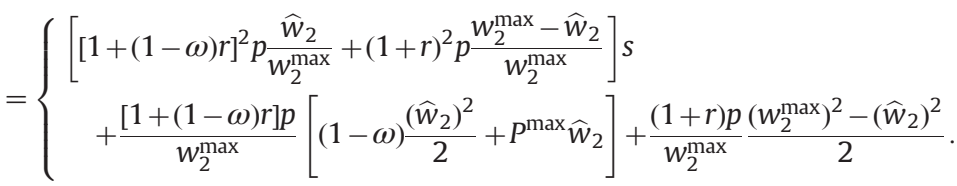

This equation may be solved for the optimal level of saving function, yielding the implicit expression

$$
\begin{aligned}
S= & \frac{(1-\tau) w_{1}-\frac{[1+(1-\omega \xi) r] p}{w_{2}^{\max }}\left[(1-\omega) \frac{\left(\widehat{w}_{2}\right)^{2}}{2}+P^{\max } \widehat{w}_{2}\right]-\frac{(1+r) p}{w_{2}^{\max }} \frac{\left(w_{2}^{\max }\right)^{2}-\left(\widehat{w}_{2}\right)^{2}}{2}}{1+[1+(1-\omega \xi) r]^{2} p \frac{\widehat{w}_{2}}{w_{2}^{\max }}+(1+r)^{2} p \frac{w_{2}^{\max }-\widehat{w}_{2}}{w_{2}^{\max }}}, \\
& =\frac{(1-\tau) w_{1}-[1+(1-\omega \xi) r] p\left[\frac{\widehat{w}_{2}}{2}+P^{\max }-\omega \frac{\widehat{w}_{2}}{2}\right]\left(\frac{\widehat{w}_{2}}{w_{2}^{\max }}\right)-(1+r) p \frac{\left(w_{2}^{\max }+\widehat{w}_{2}\right)}{2}\left(1-\frac{\widehat{w}_{2}}{w_{2}^{\max }}\right)}{1+[1+(1-\omega \xi) r]^{2} p \frac{\widehat{w}_{2}}{w_{2}^{\max }}+(1+r)^{2} p\left(1-\frac{\widehat{w}_{2}}{w_{2}^{\max }}\right)},
\end{aligned}
$$

where $\widehat{w}_{2}=\bar{y}_{2}-r s$.

Government: The government budget clearing condition is

$$
\frac{w_{1} \tau}{p}=\int_{y_{2}^{\min }}^{\bar{y}_{2}} \operatorname{Pf}\left(y_{2}\right) d y_{2}
$$




$$
\begin{aligned}
& =\int_{y_{2}^{\min }}^{\bar{y}_{2}}\left(P^{\max }-\omega y_{2}\right) f\left(y_{2}\right) d y_{2}, \\
& =\int_{0}^{\widehat{w}_{2}}\left(P^{\max }-\omega\left(w_{2}+\xi r s\right)\right) f\left(w_{2}\right) d w_{2} \text {, } \\
& =\left.\frac{1}{w_{2}^{\max }}\left(P^{\max } w_{2}-\omega\left(\frac{w_{2}}{2}+\xi r s\right) w_{2}\right)\right|_{0} ^{\widehat{w}_{2}}, \\
& =\overbrace{\frac{\widehat{w}_{2}}{w_{2}^{\max }}}^{\text {\# of pensioners }} \overbrace{\left(P^{\max }-\omega\left(\frac{\widehat{w}_{2}}{2}+\xi r s\right)\right)}^{\text {Averageold-age pension benefit }},
\end{aligned}
$$

where $s$ is optimal saving and $\widehat{w}_{2}=\bar{y}_{2}-\xi r s$.

Equilibrium. The equilibrium conditions for this simple economy reduce to

$$
\begin{aligned}
s^{*} & =\frac{\left(1-\tau^{*}\right) w_{1}-[1+(1-\omega \xi) r] p\left[\frac{\widehat{w}_{2}^{*}}{2}+P^{\max }-\omega \frac{\widehat{w}_{2}^{*}}{2}\right]\left(\frac{\widehat{w}_{2}^{*}}{w_{2}^{\max }}\right)-(1+r) p \frac{\left(w_{2}^{\max }+\widehat{w}_{2}^{*}\right)}{2}\left(1-\frac{\widehat{w}_{2}^{*}}{w_{2}^{\max }}\right)}{1+[1+(1-\omega \xi) r]^{2} p \frac{\widehat{w}_{2}^{*}}{w_{2}^{\max }}+(1+r)^{2} p\left(1-\frac{\widehat{w}_{2}^{*}}{w_{2}^{\max }}\right)} \\
\tau^{*} & =\frac{p}{w_{1}}\left[\frac{\widehat{w}_{2}^{*}}{w_{2}^{\max }}\left(P^{\max }-\omega\left(\frac{\widehat{w}_{2}^{*}}{2}+\xi r s^{*}\right)\right)\right], \\
\widehat{w}_{2}^{*} & =\bar{y}_{2}-\xi r s^{*} .
\end{aligned}
$$

These equilibrium conditions simultaneously determine the solutions for $\left(s^{*}, \tau^{*}, \widehat{w}_{2}^{*}\right)$. The first is the optimal saving function. The second equation determines the tax rate, $\tau^{*}$, that ensures a government budget balance. The final equation determines the period 2 (extensive margin) wage rate, $\widehat{w}_{2}^{*}$, that separates pensioners from non-pensioners. Note that $P^{\text {max }}, \omega$ and $\bar{y}_{2}$ are exogenously set by the government.

\section{A.2. General equilibrium model: algorithm to solve the model}

We follow the algorithm in Auerbach and Kotlikoff (1987) to solve the model. The general procedure to solve for general equilibrium is summarized as follows:

1. Discretize the state space of assets as $\left[a_{0}, \ldots, a_{\max }\right]$.

2. Guess an initial wage rate, $w$, and endogenous government policy variables while taking the world interest rate as given.

3. Work backwards from period $J$ to period 1 to obtain decision rules for consumption, savings, labor supply, and the value and marginal value functions of the household.

4. Iterate forwards to obtain the measure of households across states, using the household decision rules and the laws of motion for working ability shocks and mortality shocks and taking the distribution of agents of age 1 as given.

5. Aggregate labor supply and clear the labor market to get a new wage rate; balance the government budget to determine endogenous government variables.

6. Check the relative change in aggregate variables after each iteration and stop the algorithm when the change is sufficiently small $\left(10^{-4}\right.$ percent). Otherwise, repeat steps from 3 to 6 .

\section{References}

Auerbach, J.A., Kotlikoff, L.J., 1987. Dynamic Fiscal Policy. Cambridge University Press, Cambridge.

Chou, S.-Y., Liu, J.-T., Huang, C.J., 2004. Health insurance and savings over the life cycle semiparametric smooth coefficient estimation. J. Appl. Econom. 19 (3), 295-322.

Conesa, J., Krueger, D., 1999. Social security reform with heterogeneous agents. Rev. Econ. Dyn. 2, 757-795.

De Nardi, M., French, E., Jones, B.J., 2010. Why do the elderly save? The role of medical expenses. J. Polit. Econ. 118 (1), 39-75.

Diamond, P., Mirrlees, J., 1978. A model of social insurance with variable retirement. J. Publ. Econ. 10 (3), 295-336.

Diamond, P., Mirrlees, J., 1986. Payroll-tax financed social insurance with variable retirement. Scand. J. Econ. 88 (1), 25-50.

Disney, R., Smith, S., 2002. The labour supply effect of the abolition of the earnings rule for older workers in the United Kingdom. Econ. J. 112 (478), 136-152. Feldstein, M.S., 1987. Should social security benefits be means tested? J. Polit. Econ. 95 (3), 468-484.

Friedberg, L., 2000. The labor supply effects of the social security earnings test. Rev. Econ. Stat. 82, 48-63.

Friedman, M., Cohen, W., 1972. Social Security, Universal or Selective?. American Enterprise Institute for Public Policy Research, Washington.

Fuster, L., Imrohoroglu, A., Imrohoroglu, S., 2003. A welfare analysis of social security in a dynastic framework. Int. Econ. Rev. 44 (4), 1247-1274.

Fuster, L., Imrohoroglu, A., Imrohoroglu, S., 2007. Elimination of social security in a dynastic framework. Rev. Econ. Stud. 74 (1), 113-145.

Golosov, M., Tsyvinski, A., 2006. Designing optimal disability insurance: a case for asset testing. J. Polit. Econ. 114 (2), 257-279.

Gruber, J., Wise, D., 1999. Social Security and Retirement around the World. University of Chicago Press, Chicago. 
Gruber, J., Yelowitz, A., 1999. Public health insurance and private savings. J. Polit. Econ. 107 (6), $1249-1274$.

Heer, B., 2002. The German unemployment compensation system: effects on aggregate savings and wealth distribution. Rev. Income Wealth 48, 371-394. Hubbard, R.G., Judd, K., 1987. Social security and individual welfare: precautionary saving, borrowing constraints, and the payroll tax. Am. Econ. Rev. 77 (4), 630-646.

Hubbard, R.G., Skinner, J., Zeldes, S.P., 1995. Precautionary saving and social insurance. Journal of Political Economy 103 (2), $360-399$.

Imrohoroglu, A., Imrohoroglu, S., Jones, D.H., 1995. A life cycle analysis of social security. Econ. Theory 6 (1), 83-114.

Krueger, D., Kubler, F., 2006. Pareto-improving social security reform when financial markets are incomplete!? Am. Econ. Rev. 96 (3), 737-755. http://www. jstor.org/stable/30034069.

Kudrna, G., Woodland, A., 2011. An intertemporal general equilibrium analysis of the Australian Age Pension Means Test. J. Macroecon. 33, 61-79.

Kumru, C., Piggott, J., 2009. Should public retirement provision be means-tested? ASB Research Paper No. 2009 AIPAR 01.

Maattanen, N., Poutvaara, P., 2007. Should old-age benefits be earnings-tested? IZA Discussion Papers 2616.

Neumark, D., Powers, E., 1998. The effect of means-tested income support for the elderly on pre-retirement saving: evidence from the SSI Program in the U.S. J. Publ. Econ. 68 (2), 181-206.

Neumark, D., Powers, E., 2000. Welfare for the elderly: the effects of SSI on pre-retirement labor supply. J. Publ. Econ. 78, 51-80.

Nishiyama, S., Smetters, K., 2007. Does social security privatization produce efficiency gain? Q. J. Econ. 122, 1677-1719.

Powers, E.T., 1998. Does means-testing welfare discourage saving? Evidence from a change in AFDC policy in the United States. J. Publ. Econ. 68 (1), $33-53$.

Sefton, J., van de Ven, J., 2009. Optimal design of means tested retirement benefits. Econ. J. 119, F461-F481.

Sefton, J., van de Ven, J., Weale, M., 2008. Means testing retirement benefits: fostering equity or discouraging savings? Econ. J. 118 (528), 556-590.

Varian, H.R., 1980. Redistributive taxation as social insurance. J. Publ. Econ. 14, 49-68.

Wooden, M., Freidin, S.F, Watson, N., 2002. The household, income and labour dynamics in Australia (HILDA) survey: wave 1. Aust. Econ. Rev. 35, 339-348. 